San Jose State University

SJSU ScholarWorks

Master's Theses

Master's Theses and Graduate Research

1995

\title{
The meaning of work for men with spinal cord injury : implications for impatient rehabilitation
}

Susan Meredith Cooke

San Jose State University

Follow this and additional works at: https://scholarworks.sjsu.edu/etd_theses

\section{Recommended Citation}

Cooke, Susan Meredith, "The meaning of work for men with spinal cord injury : implications for impatient rehabilitation" (1995). Master's Theses. 984.

DOI: https://doi.org/10.31979/etd.9m6t-5uhw

https://scholarworks.sjsu.edu/etd_theses/984

This Thesis is brought to you for free and open access by the Master's Theses and Graduate Research at SJSU ScholarWorks. It has been accepted for inclusion in Master's Theses by an authorized administrator of SJSU ScholarWorks. For more information, please contact scholarworks@sjsu.edu. 


\section{INFORMATION TO USERS}

This manuscript has been reproduced from the microfilm master. UMI films the text directly from the original or copy submitted. Thus, some thesis and dissertation copies are in typewriter face, while others may be from any type of computer printer.

The quality of this reproduction is dependent upon the quality of the copy submitted. Broken or indistinct print, colored or poor quality illustrations and photographs, print bleedthrough, substandard margins, and improper alignment can adversely affect reproduction.

In the unlikely event that the author did not send UMI a complete manuscript and there are missing pages, these will be noted. Also, if unauthorized copyright material had to be removed, a note will indicate the deletion.

Oversize materials (e.g., maps, drawings, charts) are reproduced by sectioning the original, beginning at the upper left-hand corner and contiming from left to right in equal sections with small overlaps. Each original is also photographed in one exposure and is included in reduced form at the back of the book.

Photographs included in the original manuscript have been reproduced xerographically in this copy. Higher quality $6^{\prime \prime} \times 9^{n}$ black and white photographic prints are available for any photographs or illustrations appearing in this copy for an additional charge. Contact UMI directly to order.

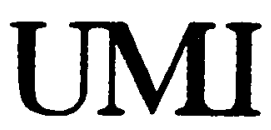

A Bell \& Howell Information Company

300 North Zeeb Road. Ann Afbor. M1 48106-1346 USA

$313: 761-4700 \quad 800: 521-0600$ 

THE MEANING OF WORK

FOR MEN WITH SPINAL CORD INJURY:

IMPLICATIONS FOR

INPATIENT REHABILITATION

\author{
A Thesis \\ Presented to \\ The Faculty of the Department of Occupational Therapy \\ San Jose State University \\ In Partial Fulfillment \\ of the Requirements for the Degree \\ Master of Science
}

by

Susan Meredith Cooke

May, 1995 
UMI Number: 1374575

UMI Microform 1374575

Copyright 1995, by UMI Company. All rights reserved.

This microform edition is protected against unauthorized copying under Title 17, United states Code.

\section{UMI \\ 300 North Zeeb Road \\ Ann Arbor, MI 48103}


APPROVED FOR THE DEPARTMENT OF OCCUPATIONAL THERAPY

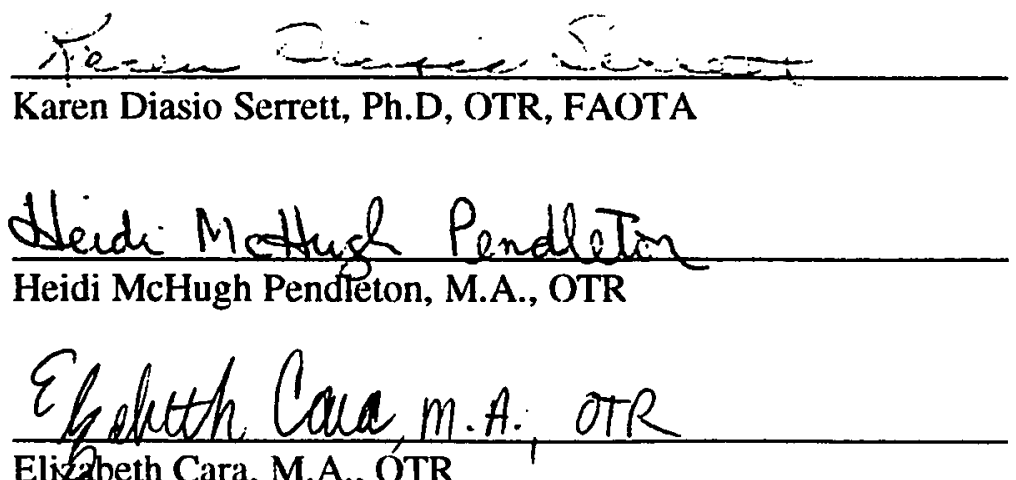

Elizabeth Cara, M.A., OTR

APPROVED FOR THE UNIVERSITY

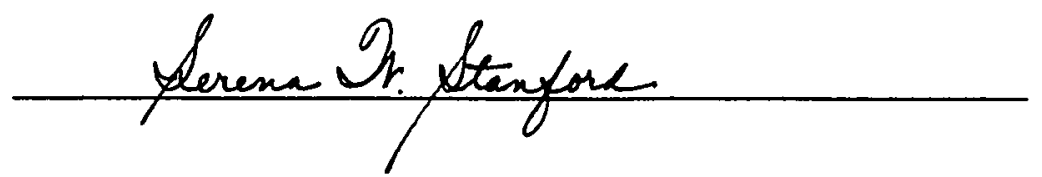


(ㄷ) 1995

Susan Meredith Cooke

ALL RIGHTS RESERVED 


\author{
Abstract \\ The Meaning of Work for Men with Spinal Cord Injury: \\ Implications for Inpatient Rehabilitation \\ by Susan Meredith Cooke
}

This study examined the influence of the meaning of work on employment after a spinal cord injury, and the significance of the findings for inpatient occupational therapy. In-depth, qualitative interviews were conducted with five men with spinal cord injury regarding their work lives. The data were analyzed for common themes in the meaning of work, factors affecting employment, difficulties in returning to work, and participants' perceptions of the effectiveness of occupational therapy in addressing vocational needs.

Work was found to be an important source of independence, activity, respect, and pride. Factors such as the increased survival of persons with high-level injuries, shorter hospital stays, and increasing demands for functional goals may affect an occupational therapist's role. Occupational therapists can advance patients toward meaningful employment by providing them with opportunities for control, being aware of current research, and by acknowledging that vocational development will be ongoing long after discharge. 


\section{Acknowledgments}

I would like to express my profound appreciation to the many people who helped with the completion of this thesis under daunting time constraints.

To my advisor, Dr. Karen Diasio Serrett, thank you for guiding me through a seemingly impossible mission and helping me clarify my thoughts. Thank you for your time, your kind words of caring, and your reminders to believe in my abilities.

Thank you to Assistant Professor Hcidi McHugh Pendleton for your careful editing, your thoughtful suggestions, your much-needed encouragement, and your assistance in recruiting participants.

Thank you to Assistant Professor Elizabeth Cara for your valuable input and your willingness to listen and make suggestions as I struggled to begin this process.

Thank you to Dr. Lela Llorens for your assistance with my proposal, for sharing your knowledge of research methodologies, and for your help with final editing.

Thank you to Amy Killingsworth, Chair of the Occupational Therapy Department at San Jose State University, for taking time from your dizzying schedule to be my cheerleader and a vital source of information.

Thank you to Lisa Brewer, MSW and to the occupational therapy staff at Kaiser Foundation Rehabilitation Center for your assistance in referring me to potential participants.

Thank you to Suzanne Blakeslee for your prompt, precise transcription. 
I would like to acknowledge the patience and understanding of all of my friends and family members as I struggled to meet deadlines. Special thanks go to my parents, Emmett and Carol, for your hours of editing and your unwavering support; to my sister, Nancy, for your encouragement and for helping me with computer literacy; and to my friend Gay for your moral support, good talks, and long walks.

A very important thank you goes to my husband, Robert. Thank you for holding my hand through the whole process, for encouraging me to carry on, and for supporting me in so many ways. I guess it is my turn to walk the dog!

Finally, and most importantly, thank you to the five dynamic men who were gracious enough to share your stories with me. I left each interview with a combined sense of awe and humility because of your determination to succeed, your spirit, and your lack of self-pity. I hope that I did justice to the thoughts and feelings behind your words. 
TABLE OF CONTENTS

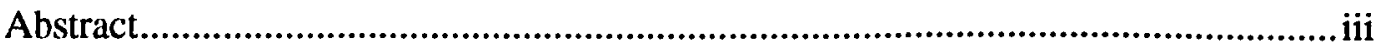

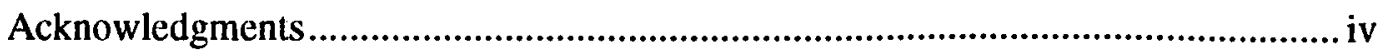

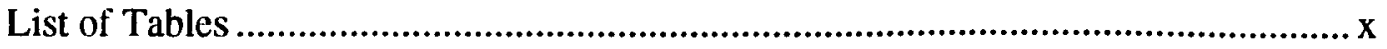

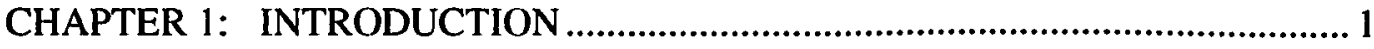

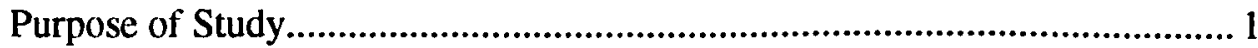

Statement of the Problem ........................................................................ 1

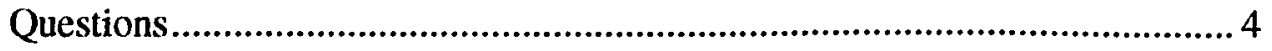

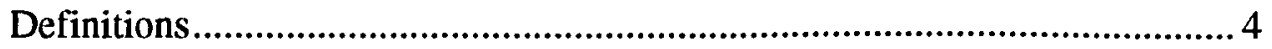

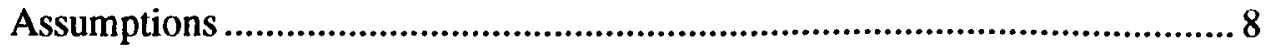

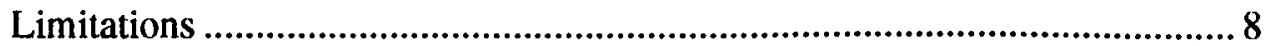

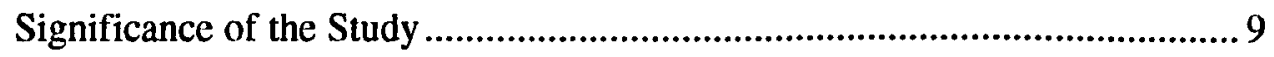

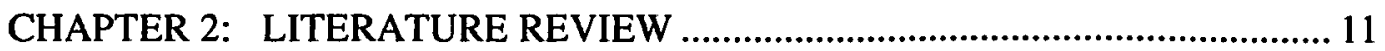

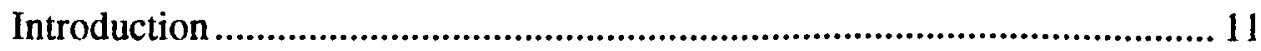

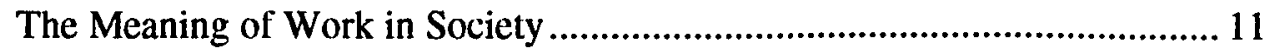

The Meaning of Work to a Person with Severe Disability ......................... 13

Alternatives to Employment .............................................................. 15

Factors That Affect Return to Work....................................................... 16

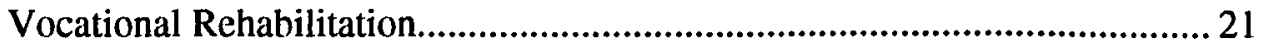

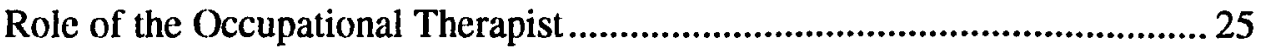


Occupational Therapy Frame of Reference ............................................. 30

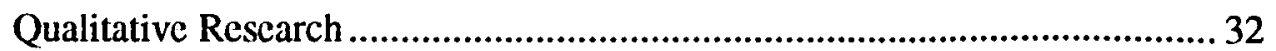

Summary of the Literature Review ....................................................... 34

CHAPTER 3: DESIGN AND METHODOLOGY ............................................. 37

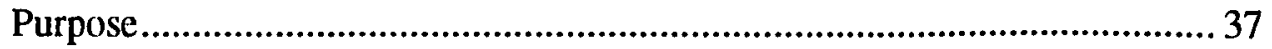

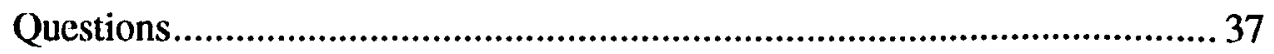

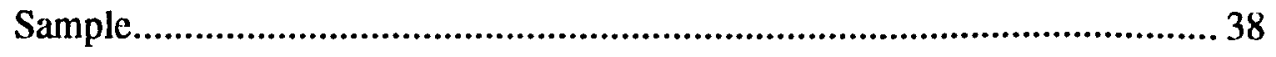

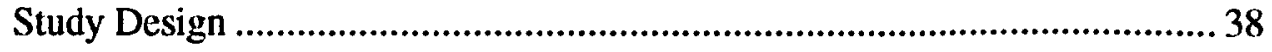

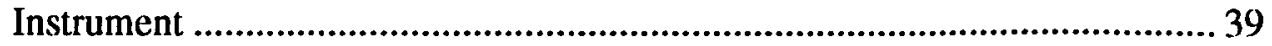

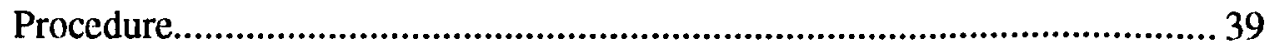

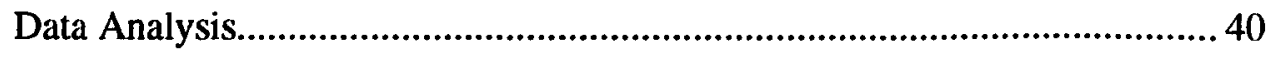

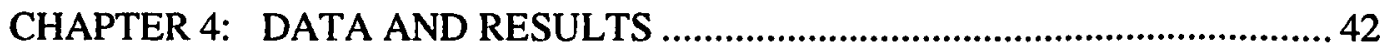

Presentation of Data....................................................................... 42

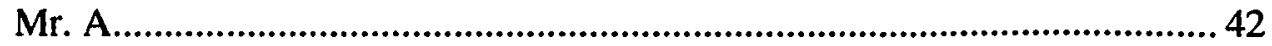

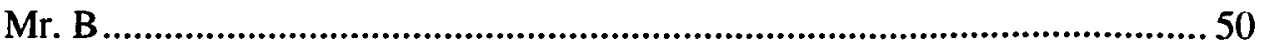

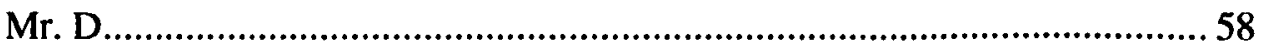

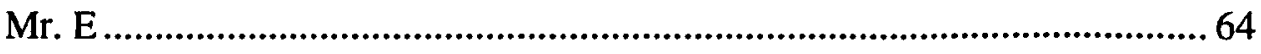

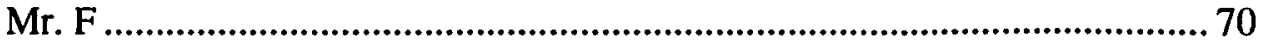




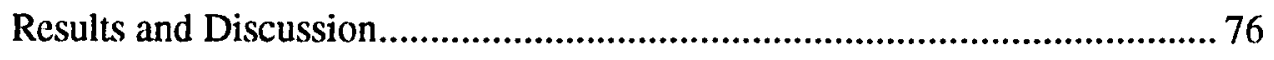

The Meaning of Work................................................................... 76

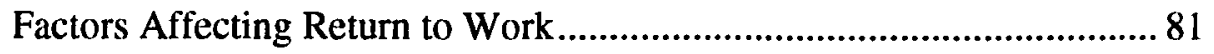

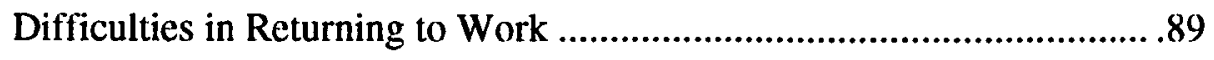

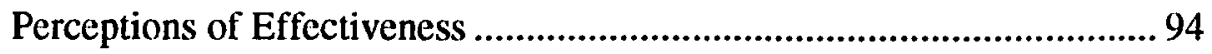

Participants' Recommendations ............................................... 100

\section{CHAPTER 5: PROFESSIONAL IMPLICATIONS}

RECOMMENDATIONS AND SUMMARY ........................... 105

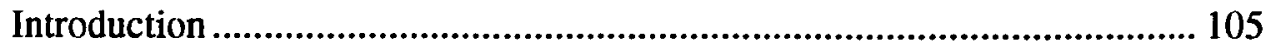

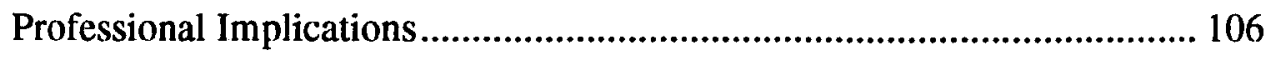

Factors in Addressing Vocational Issues .......................................... 106

Significance of the Meaning of Work .............................................. 113

Implications Related to the Model of Human Occupation ....................... 115

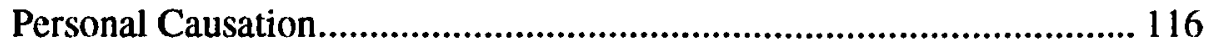

Valued Goals and Interests..................................................... 117

Meaning............................................................................ 117

Recommendations for Further Research............................................... 118

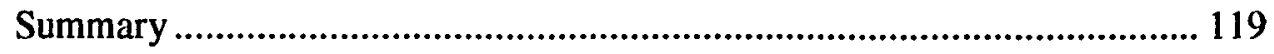

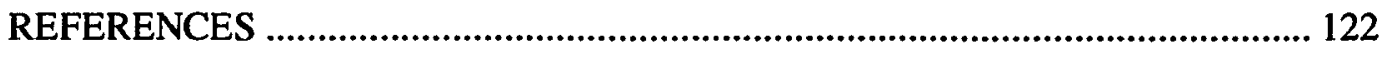




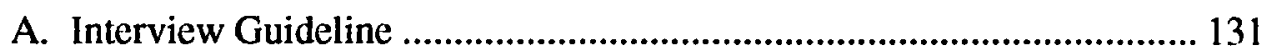

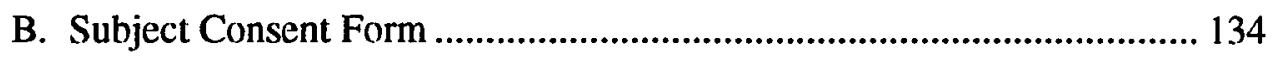

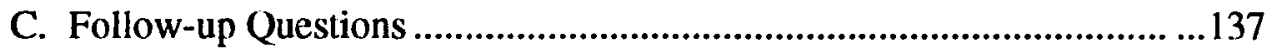




\section{List of Tables}

Table

Page

1 Demographic Information............................................................43

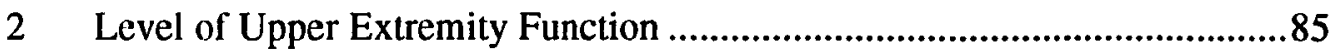

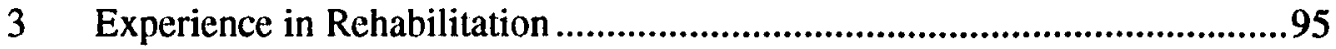




\section{CHAPTER 1}

\section{INTRODUCTION}

\section{Purpose}

The purpose of this study was to explore how the meaning of work affects the future employment of men with spinal cord injury, and the implications of the findings for occupational therapists who work with this population in a rehabilitation hospital setting for patients with acute or subacute diagnostic conditions.

\section{Statement of the Problem}

Work is an essential element in the lives of most adults. It structures their days, provides opportunities for social interaction, identifies their standing in society, and is a source of pride and financial independence, all of which affect self-esteem. One of the most important goals of many people with spinal cord injuries is to secure a job, yet most people with spinal cord injury are not employed and of those who are, only a small percent work full-time (DeVivo, Rutt, Stover, \& Fine, 1987; Krause, 1992).

There are substantial difficulties encountered by persons with disabilities in the process of returning to work, but the failure to achieve employment is due partly to rehabilitation programs that fail to tap patient resources (Siegel, 1974), In order to tap those resources, rehabilitation professionals must incorporate into treatment an understanding of a patient's needs and his/her motivation to take an active role in rehabilitation. Encouraging active participation is an important factor in addressing 
vocational issues (Kanellos, 1985). Research has shown, however, that health care professionals may not clearly understand their rehabilitation patients' needs and may not give the patients enough information to allow them to fully participate in the rehabilitation process. Studies have also shown that hospital staff members who work with patients with spinal cord injuries have a different perception of their patients' state of mind than is actually being experienced by the patients (Cushman \& Dijkers, 1990; Ernst, 1987). They may differ from the patients in their assessment of the patients' current problems (Krause \& Crewe, 1990). One study found that occupational therapists differed from their spinal cord-injured patients in the meaning or purpose which they attributed to activities (Yerxa \& Locker, 1990). This could lead to a lack of understanding of the overall goals of therapy, which could impact on a patient's motivation to participate. When patients are unclear about the rehabilitation process and its goals, it may affect their perception of the efficacy of rehabilitation (Krishnan, Glass, Jackson, \& Bingley, 1988).

The theory and philosophy of occupational therapy have historically been supportive of vocational activity. This area of practice declined during the 1950's and 1960's (Harvey-Krefting, 1985), but since the early 1970's there has been a great deal of research and clinical practice growth in the area of work hardening, which is performed primarily in a non-hospital setting (Ellexson, 1989; King, 1992). There is a paucity of recent literature by occupational therapists regarding the role of occupational therapy in meeting the vocational needs of persons with spinal cord injuries who are in a rehabilitation hospital setting. Several factors could require changes in that role, 
including shorter hospital stays, reimbursement issues, and increased survival rates of persons with high level injuries.

The Model of Human Occupation addresses the importance of allowing an individual's valued goals and intercsts to guide occupational therapy, so that after an injury or illness, they may resume old roles or assume new ones. The vocational needs of people with spinal cord injuries, and their intrinsic motivation to work must be recognized, enhanced, and maintained early in the rehabilitation process (Kanellos, 1985) so that they may eventually attain the valued role of worker.

Research to discover the meaning of work to this patient population and placed in the context of occupational therapy theory is needed. One method proposed in the occupational therapy literature to discover the unique meaning that individual patients attribute to experience is through narrative reasoning (Mattingly, 1991). The use of this method with patients in the rehabilitation hospital may be difficult in the current health care climate because the therapist has less time with the patient and is often required to justify that time with functional goals. More research is needed in occupational therapy to explore the use of personal narrative to help in the discovery of the meaning that individuals attribute to activities and experience (Helfrich \& Kielhofner, 1994; Helfrich, Kielhofner \& Mattingly, 1994). 


\section{Questions}

The questions to be answered by this study are:

1. What is the meaning of work for men with quadriplegia from a spinal cord injury?

2. Which factors are most associated with a successful return to work after a spinal cord injury?

3. What are the difficulties faced by men with quadriplegia from a spinal cord injury when they return to work?

4. What are the participants' perceptions of the effectiveness of occupational therapy in addressing work issues?

5. What recommendations do the participants have for occupational therapists who work with persons with spinal cord injuries in a hospital setting for patients with acute or subacute conditions?

\section{Definitions}

Definitions generated for this study are:

Activities of daily living (ADL)--"The typical life tasks required for self-care and self-maintenance, such as grooming, bathing, eating, cleaning the house and doing laundry" (Christiansen, 1991).

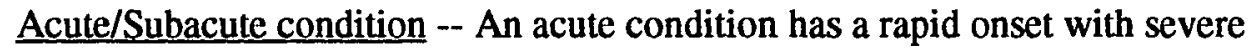
symptoms. A subacute condition is between acute and chronic or long-term, but with some acute symptoms (Thomas, 1993) For the purposes of this study, these are the 
conditions experienced by a patient with a spinal cord injury shortly after their injury until they are initially discharged from inpatient rehabilitation.

Adaptation--Any adjustment or change of beliefs, thoughts or actions in response to challenges or demands in daily life (Christiansen, 1991).

Adjustment--Generating solutions to problems (Crewe, Athelstan, \& Bower, 1978).

Employment--Guralnik (1970) defines employment as that which is keeping one busy or occupied; taking up the time and attention of; work, occupation, profession, job. For the purposes of this study, employment will refer to paid employment.

High level spinal cord injury--An injury occurring at any segmental level between the first and the fourth cervical vertebrae (Lathem, Gregorio, \& Garber, 1985). Individuals with high level injuries may be dependent on respiratory aids.

Locus of control--"The extent to which the person believes that most life events result from his/her own abilities or efforts rather than external forces" (McShane \& Karp, 1993, p. 31).

Meaning--The individual, subjective experience of the significance of an event. Having significance or purpose.

Meaningful time use--In this study, the reference is to how daily activities are organized in such a way as to be satisfying to the individual. This is an important issue for unemployed people who are lacking the externally imposed daily structure provided by most jobs.

Motivation to work -- The innate drive or impulse to hold a paid job. 
Narrative reasoning -- Clinical reasoning is the thought and decision-making that guides treatment planning. The narrative form of clinical reasoning goes beyond the assessment phase of therapy; it is on ongoing process, described by Schell \& Cervero (1993) as "an improvisational process in which reading the context of the problem from the patient's perspective is the key clinical reasoning task" (p. 607).

Occupation--Activities that are "self-initiated, goal directed, organized, composed of adaptive skills, and personally satisfying" (Yerxa \& Locker, 1990, p. 324).

Occupational therapy treatment plan--"The projected series and sequence of treatment procedures based on an individualized evaluation of what is needed to restore or improve the health and function of a patient" (Thomas, 1993, p. 2031).

Productivity--Acting to generate a result which could be a service or a product. Purposeful activity--"Tasks or experiences in which the person actively participates and that elicit coordination between physical, emotional, and cognitive systems" (Pedretti, 1990, p. 210).

Quadriplegia--'Paralysis of all four extremities and usually the trunk" (Thomas, 1993, p. 1654). There are other causes of quadriplegia, but for the purposes of this study, the etiology is an injury to the spinal cord in the cervical spine.

Rehabilitation- "The processes of treatment and education that lead the disabled individual to attainment of maximum function, a sense of well-being and a personally satisfying level of independence" (Thomas, 1993, p. 1692).

Remunerative employment--Doing a job for which one is compensated monetarily. 
Severe disability--A disability is any restriction or lack of ability to perform an activity as it would normally be performed; a severe disability prevents or limits the fulfillment of a normal life role (Christiansen, 1991). For the purposes of the present study, severe disability is defined operationally as a restriction in the ability to perform a worker role.

Spinal Cord Injury--An acute traumatic insult to the spinal cord resulting in varying degrees of loss in sensory and/or motor function, depending on the level and completeness of the injury. In this study, all of the participants had injuries in the cervical area of the spine. In referring to the level of the injury, the letter "C" precedes the number or numbers of the vertebrae affected.

Successful employment -- Maintaining full-time employment for significant periods of time.

Third-party payer -- Insurance companies or government programs that reimburse health care providers for patient care.

Vocation--"The function or career toward which one believes [oneself] to be called" (Guralnik, 1970, p. 1590).

Work-- "Physical or mental effort exerted to do or make something; purposeful activity; labor; toil. ... Employment at a job or in a position, occupation, profession, business, trade, craft, etc." (Guralnik, 1970, p. 1638). For the purposes of the present study, work will be defined operationally as remunerative employment unless otherwise specified. 


\section{Assumptions}

Assumptions held by the researcher were:

1. That work has traditionally been and continues to be an appropriate area of attention for occupational therapy evaluation and treatment in an inpatient rehabilitation hospital.

2. That occupational therapists can make a unique contribution in facilitating return to work for a person with a spinal cord injury.

3. That the meaning of work can be understood through personal narrative by capturing the essence of the lived experience of a man's working life.

\section{Limitations}

The following are limitations to this study:

1. The five participants represent a sample of convenience.

2. Findings of this study could be affected by the inherent biases of the self-report, oneon-one interview format.

3. The study focuses on the perception of historical events that cannot be confirmed by other means.

4. Although the researcher attempted to identify personal biases or preconceptions in order to keep them from affecting the interview process and data analysis, personal biases must still be considered a limitation of this study.

5. The researcher acknowledges that the results of this study cannot be generalized to women or persons from other cultures who have spinal cord injuries. 
Significance of the Study

There are several reasons why study in this area is important. The unemployment figures for men with spinal cord injuries are high, despite their apparent desire to work. The factors inhibiting employment and the factors which predict employment have been studied extensively by many disciplines, but few qualitative studies using personal narrative have been attempted. The meaning of work to an individual with a disability has not received adequate attention in the occupational therapy literature.

With the possibility that some external barriers to employment, such as architectural barriers and discrimination, will be slowly diminished due to the Americans with Disabilities Act of 1990, the intrinsic motivation for individuals with disabilities to work may take on greater significance.

It has been suggested that research is needed to understand "how the successful 'copers' go about achieving their success" (MacDonald, Nielson, \& Cameron, 1987, p. 342). The men in the current study have all maintained full-time employment for significant periods of time. This study has attempted to shed light on how these successful workers have achieved employment despite substantial obstacles.

With shorter hospital stays, greater emphasis on documentation, and increased survival of persons with high level spinal cord injuries, the role of occupational therapy in addressing work issues for persons with spinal cord injuries must be examined. This study is important because it describes significant vocational issues from the perspective of former patients. Their input could be helpful in improving the treatment of similar patients by occupational therapists. 
It is hoped that this study will encourage future phenomenological inquiry into the meaning of experience. This study may help fill the void left by what Carpenter (1994) described as a "dearth of studies" on how patients perceive rehabilitation. It is also hoped that this study will further confirm the importance and validity of a narrative approach to clinical reasoning. 


\title{
CHAPTER 2
}

\section{LITERATURE REVIEW}

\author{
Introduction
}

The review of the literature for this study has been divided into eight sections including 1) the meaning of work in society as a whole, 2) the meaning of work to a person with severe disability, 3) the factors that affect a disabled person's return to work, 3) alternatives to employment for those who are unable or unmotivated to work at a paid job, 5) vocational rehabilitation and its effectiveness, 6) the role of occupational therapy, 7) a frame of reference for occupational therapy to address work issues, and 8) a description of qualitative research.

The first section summarizes the major themes from the vast amount of literature concerning the meaning of work in American society.

\section{The Meaning of Work in Society}

Kielhofner (1983) defines work as "a behavior which is motivated by an intrinsic urge to be effective in the environment" (p. 136). Children learn early the desire to master their immediate environment; work skills and habits develop through play and childhood chores which "promote the development of a foundation of readiness skills and are a major force in shaping self-concept " (Stephens \& Pratt, 1989, p. 326). Using Maslow's hierarchy of needs, Lassiter (1977) has listed needs which are specifically met by work as: material needs, self-esteem needs, needs for activity and creativity, and for 
respect by others. American society places a high value on self-reliance, independence and autonomy (Kirshbaum, 1991). Geist and Calzaretta (1982) said that "work is the central function in the lives of most adults; it contributes to one's self-esteem and selfidentity" (p. 46). Kanellos (1985) cited Neff who said that remunerated employment is considered by many in American society to be the "... indispensable requirement for becoming an autonomous and independent adult" (p. 726).

Work can provide a major source of social interaction and can affect the entire social system of the worker by influencing the way he/she is viewed by others and the way he/she evaluates him/herself; work is a "concrete way of establishing and assessing [one's] status in life" (Geist \& Calzaretta, 1982, p. 48). Velozo (1993) contended that "work is the principle medium for expressing effectiveness in society and a major part of socialization into adulthood" (p. 203).

Besides being a source of economic security and independence, work offers structure to a daily schedule and "is useful in bringing order and meaning to one's life" (Geist \& Calzaretta, 1982, p. 46). A study in Sweden, where the work ethic is also strong, found overall satisfaction with one's vocational status to be closely associated with happiness (Branholm, Eklund, Fugl-Meyer, \& Fugl-Meyer, 1991).

A great deal of research has been conducted on the significance of work in the lives of persons with disabilities. Although this is not necessarily focused on persons with spinal cord injuries, many of the findings are applicable to this population. 
The Meaning of Work to a Person With Severe Disability

In this society, being successful at work is often construed to mean that one is a valuable person, while being a failure at work makes one worthless (Geist \& Calzaretta, 1982). This attitude could be devastating for a person who is suddenly disabled, dependent on others for basic needs, and unable to work. It is easy to overlook the importance of work when one faces the routine realities of a steady job, but after a disabling injury, work seems to take on new meaning. Branholm et al. (1991) found that for rehabilitation clients, compared with the general population, "satisfaction with vocational situation was now a singularly important predictor of life satisfaction" (p. 33). It is striking that Krause (1992) found employment to be highly correlated with survival in their prospective study of the long-term survival of persons with spinal cord injury. Eisenberg and Falconer (1978) cited a working man with paraplegia who stated that "survival without self-respect is a slow death" (p. 65).

The goal of competitive employment is highly valued by disabled people (Kanellos, 1985). The literature is ripe with references to the importance of work to the overall quality of life of persons with disabilities. In a study of the quality of life of forty-three persons with spinal cord injuries who were ten or fifteen years post-injury, Cushman and Hasset (1992) found that the group with a lower self-reported quality of life had a significantly lower rate of ever having looked for a job since their injury. On a follow-up visit, vocational rehabilitation clients, who had either returned to work or were in educational or vocational training were found to have "increased their levels of satisfaction with ADL, leisure, vocational and financial situations" (Branholm et al., 
1991, p. 33). In a study of 98 patients with traumatic spinal cord injuries, gainful employment was the only demographic factor associated with a high reported quality of life (Lundqvist, Siosteen, Blomstrand, Lind, \& Sullivan, 1991). Another study of life satisfaction among persons with spinal cord injuries found employment and money matters (which could directly relate to employment) among the areas with the lowest reported satisfaction (Fuhrer, Rintala, Hart, Clearman, \& Young, 1992), possibly reflecting the high unemployment rate of persons with spinal cord injuries (Krause, 1992).

On the other hand, not all researchers found remunerative employment to be the most important goal for every disabled person. Crewe et al. (1978) reported that "individual differences characterize the response to disability as well as to every other important aspect of life" (p. 15). Mills (1973) wrote, "Work may be a mere source of livelihood or the most significant part of one's inner life. . . Neither love nor hatred of work is inherent in man, or inherent in any given line of work" (p. 203). In other words, although research has shown that employment is highly valued by many persons with disabilities, it must not be assumed that it is the goal for every individual.

Because many people with spinal cord injuries are not working, the next section of the literature review will explore the possibilities for meaningful time use by those who are unemployed. 
Alternatives to Employment

Considering the far-reaching importance placed on work, how does one adjust to the loss of the worker role as a result of a severe disability? Historically, employment has been considered one of the most important rehabilitation goals, and many State Rehabilitation Departments still define successful rehabilitation as full-time employment (Krause, 1992; Trieschmann, 1980).

Trieschmann (1980) stressed that employment is only one behavior that constitutes a successful life, and suggested that the emphasis of vocational rehabilitation should be on productivity, not strictly on employment. Productivity would include vocational endeavors, education, volunteer activities, and avocational pursuits. In referring to Maslow's motivational theory, it is Lassiter's (1977) opinion that in a work adjustment program, self-actualization needs, for many people, may be met through avocations and hobbies instead of through employment. In a study of five men with spinal cord injuries, it was found that volunteer work can not only substitute for career opportunities, but can provide structure in daily life as well (Bozzacco, 1993).

Lassiter (1984) has suggested that there are reasons to incorporate an existential viewpoint in rehabilitation counseling for the severely disabled. He stated that the two primary themes of traditional rehabilitation, interaction and achievement, may not be enough for the person with severe disability who is often isolated. He suggested that "a rich inner life" (p. 157) may make being alone less painful; it could provide an area for freedom and autonomy, and an opportunity to find peace of mind.

With fewer than $50 \%$ of persons with spinal cord injuries working at any one time 
Krause, 1992), the question arises regarding the meaning that is attributed to other activities which fill the time normally taken by a job. Yerxa and Locker (1990) conducted a study of the self-perceived quality of time use of fifteen adults with spinal cord injuries. The results showed significant differences in how individuals classify activities into categories such as Work and Self-Maintenance. The researchers suggested that activity analysis cannot be limited to the inherent qualities of the activity, but must include an understanding of the patient's experience and his/her goals for engaging in a particular activity. They said that "a final challenge for occupational therapists is to discover alternative satisfying uses of time" (p. 325) for the patient with spinal cord injury who is not working. The meaning of work for individuals must be determined in order to then determine what occupations could fulfill those meanings.

There are substantial barriers to returning to work for persons with a spinal cord injury. The following section presents the factors found in the literature to be the most predictive of successful adjustment to those difficulties.

\section{Factors That Affect Return to Work}

There is evidence to suggest that most persons are capable of working after a spinal cord injury, but fewer than $50 \%$ of them are working at any one time (Krause, 1992). Of the number working, only a small percent work full-time (Wehman \& Moon, 1988). People with spinal cord injuries have a significantly lower income level than the nondisabled population (Yerxa \& Locker, 1990), possibly reflecting the lower employment rate. A 1986 Harris poll found that although $2 / 3$ of the 124 million disabled people in 
America between 16 and 64 years old were not working, the majority of them wanted to work (Maddox, 1987). Cromwell (1985) has suggested that "adapting to role function in work roles [is] the greatest concern and priority of the disabled" (p. 21). Research has been conducted within many disciplines in an attempt to discover why the employment rate is low in a population that apparently wants to work.

Many studies have been undertaken to discover the factors that contribute to successful vocational rehabilitation of persons with spinal cord injuries. There is disagreement in the literature as to the effect of the level of injury on employment potential. Castle (1994) investigated the employment of 114 persons with spinal cord injury who were one to seven years post-injury and found that individuals with paraplegia had higher employment rates than those with quadriplegia. One study found that persons with higher injuries are less likely to drive their own vehicle, which interferes with their employment potential (McShane \& Karp, 1993). This study also found that the motivation to work was associated with the level of injury. The authors conjectured that this finding could reflect realistic expectations about returning to work, or it could be that these individuals changed their emphasis on other life activities. In another study, the only difference in employment between persons with quadriplegia and those with paraplegia was that those with paraplegia were more likely to return to their former job (Krause, 1992).

In 1974 , O'Connor and Leitner referred to people with quadriplegia who have the will to go to work as the minority. This assertion may reflect the limited vocational options available at that time. The advent of computer technology has increased the 
possibility for meaningful employment for persons with severe disabilities (Hammell, 1991; Lathem et al., 1985).

The greatest predictor of post-injury employment is one's level of education. Having a high school diploma gives individuals a decided advantage with a 50 percent employment rate compared with a 32 percent rate for those without a diploma (73 percent and 63 percent respectively having worked at some time since injury). For those with a four-year college degree, the employment rate jumps dramatically to 72 percent, with 93 percent having worked at some time post-injury (Krause, 1992).

Other predictors of employment include being of a younger age presently and at the time of injury, being male, being white, being highly motivated, having sufficient functional ability, having social support, and being employed prior to the injury (DeVivo \& Richards, 1992; Lammertse \& Yarkony, 1991; McShane \& Karp, 1993).

Personality characteristics and vocational outcome have been found to be interdependent (Crewe et al., 1978). Problem-solving ability is an important factor for eventual employment (Crewe et al., 1978) and it is one of the factors mentioned as important to address during rehabilitation treatment (Kanellos, 1985). Providing opportunities for independent problem-solving is related to an individual's perception of control over a situation, another factor that may be important for future employment.

An internal locus of control is mentioned often in the literature as a predictor of successful general adjustment to a spinal cord injury (Kanellos, 1985; McShane \& Karp, 1993; Sullivan, 1990). Frank and Elliot (1987) found that patients who took full responsibility for their health adapted successfully as well as those who believed that the 
medical professionals were responsible. Those patients who believed that their recovery was a matter of fate appeared to have the greatest difficulty.

There are substantial barriers to employment for a person with spinal cord injury, including difficulties with transportation and attendant care (DeVivo \& Richards, 1992; Krause, 1992). Wheelchair mobility and position restrictions were found to have a negative impact on developing a satisfying career (Bozzacco, 1993). Bowel and bladder management can be difficult when an individual returns to the workplace (Klemz \& Modi, 1992).

Financial disincentives are a major barrier to employment for some individuals with spinal cord injury (DeVivo \& Richards, 1992; Lammertse \& Yarkony, 1991). Zwecker (1991) outlined the two disability programs within the Social Security Administration. The first is for individuals who worked a "requisite number of calendar quarters" (p. 707) before his/her injury. These individuals are insured based on their earnings. The average Disability Insurance Benefit (DIB) in 1991 was $\$ 1,022$ per month for a disabled worker with a spouse and children.

Supplemental Security Income (SSI) is the second disability program described by Zwecker (1991). This is for disabled individuals with "minimal income and resources" and can be collected by an individual who has never worked (p. 21). If a disabled individual receives more than $\$ 407.00$ per month in other income, his/her SSI benefits will be discontinued. An eligible individual may only own up to $\$ 2,000$ in resources, discounting a home and one automobile. Neither of these programs includes any reward for finding a job; individuals are penalized by loss of all benefits if they become 
employed. The participants in Bozzacco's (1993) study of five men with spinal cord injuries spoke of having to work under the table because they would not be able to earn very much before their government benefits, including their health insurance, would be terminated. The loss of health benefits could be devastating to persons with spinal cord injuries because it may be impossible for them to obtain private health insurance (Lammertse \& Yarkony, 1991).

For persons who require attendant care for performance of daily living activities, the loss of benefits could be disastrous. Klemz and Modi (1992) chronicled the experience of one man with a spinal cord injury as he returned to work after rehabilitation. The subject lost all of his benefits from Social Security and Disability Insurance, and Medicare after he had worked for nine months in a full-time job. The government no longer considered him disabled since he was gainfully employed. He said that he would have been unable to be employed if he did not live at home and have his attendant care needs met by his father.

Some of the environmental obstacles to employment, such as architectural barriers and discriminatory hiring practices are addressed in Title I of the Americans With Disabilities Act of 1990 (ADA) (Rybski, 1992). This law affords individuals with disabilities their basic civil rights in the workplace. Kirshbaum (1991) wrote that although passage of the ADA indicated that the needs and rights of people with disabilities are being considered, they are still viewed in society as different and deficient. This observation was echoed by Trieschmann (1992) who noted that society often sends the message to a person with a spinal cord injury that he/she does not belong, 
is different, and is a second class citizen. The Americans with Disabilities Act will make persons with disabilities more visible to the public (Ditunno \& Formal, 1994), but will not solve problems of discrimination and architectural barriers overnight (DeVivo \& Richards, 1992).

Lammertse and Yarkony (1991) have confirmed that people with spinal cord injuries have unique functional problems related to aging which could affect employment. An interaction has been found between disability and the aging process. Long-term wheelchair use can affect the upper extremity joints, aging skin may have a higher risk of complications, a "decreased respiratory reserve" (p. S-310) may increase the vulnerability to respiratory complications, and the natural decrease in bowel motility could be a problem.

The above factors, which may influence the eventual employment of persons with spinal cord injuries, must be recognized by professionals when treating a patient in the rehabilitation hospital. The following section addresses the efficacy of rehabilitation services to meet the vocational needs of patients with spinal cord injuries.

\section{Vocational Rehabilitation}

A person with a disabling spinal cord injury is eligible to receive support through a state vocational rehabilitation service as long as he/she meets the requirements of being disabled and able to benefit from the service in terms of employability (Zejdlik, 1992). Due to funding cutbacks, however, the number of people with spinal cord injuries who became clients at State Departments of Vocational Rehabilitation, declined by one half 
between 1974 and 1990 (DeVivo \& Richards, 1992).

Historically, the assumption that severely disabled people have no vocational potential has had a profound effect on the availability of vocational services; people with spinal cord injuries were considered poor prospects for employment by vocational counselors (Siegel, 1974). Three factors appear to be changing this attitude. First, the advent of computers has increased the vocational options for people with high level injuries and research is being conducted regarding adaptation of the workplace to meet their needs (Garber, 1985; Taylor, Cupo, \& Sheredos, 1993). Second, the independent living movement of the 1970's increased the expectations of persons with spinal cord injuries (DeJong \& Batavia, 1991). And third, the passage of Title I of the Americans with Disabilities Act mandated increased access to employment even for the most severely disabled person, as long as he/she can perform the job tasks with reasonable accommodations (Rybski, 1992).

The factors affecting successful rehabilitation have been studied extensively. The literature was reviewed for studies on the efficacy of rehabilitation, not only in the area of vocational issues, but for strategies that have promoted success in adaptation to a disability. Successful rehabilitation depends on tapping patient resources and developing attitudes that facilitate rehabilitation (Siegel, 1974; Walker, 1974), but rehabilitation professionals seem to lack understanding of the frame of mind of their patients with spinal cord injury. Krause and Crewe (1990) discovered a discrepancy between the rehabilitation staff and clients' perceptions of the clients' current problems, which led to some clients being labeled unmotivated or rebellious. Ernst (1986) found that 
rehabilitation and research professionals tended to overestimate the depression, anxicty, and social discomfort experienced by their patients with spinal cord injuries, and underestimated their optimism. In a study of newly injured patients with spinal cord injuries and staff members of the admitting hospitals, Cushman and Dijkers (1990) found that the staff members consistently overestimated the level of depression actually experienced by the patients themselves.

Lack of information from professionals to patients was cited in the literature as detrimental to adjustment following a spinal cord injury. There is evidence that patients in rehabilitation hospitals do not receive adequate information about the goals of rehabilitation to allow for their active participation in the rehabilitation process (Glass, Krishnan, \& Bingley, 1991). A patient's active participation in therapy could increase the sense of control over the environment which Kanellos (1985) identified as being an important factor in enhancing vocational outcomes.

The applicability to community living of the information that patients receive has been questioned. Crisp (1992) found that lack of information about employment opportunities was considered by persons with spinal cord injuries who live in the community to be a significant problem in vocational decision-making. It is the belief that if vocational options were provided to patients during rehabilitation, it could facilitate later adjustment in the community. In Carpenter's (1994) study of the patients' perspective of the rehabilitation experience, the participants experienced a gap between what was taught in the hospital and what was required in the community. Although specifics were not provided, one participant said that the information learned in 
rehabilitation did not apply when he got into his home situation. Pendleton (1990) found that independent living skills, considered to be vital upon returning to the community, are under-represented in occupational therapy treatment planning and Velozo (1993) found current work assessment instruments to be limited by their lack of focus on an actual work environment.

In 1974, Walker predicted that ". . . until we are able to improve the quality of programs in the psychological, social, and vocational areas as well as medical, the percentage of quadriplegics who become employed will continue to remain low"(p. 134). In 1985, Cromwell lamented that occupational therapy educators and practitioners seemed to be focused more on "pathology reduction or restoration within the context of [the] medical model rather that the bio-social model that addresses long-range needs" including vocational needs (p. 21). Economic pressures on hospitals to decrease the length of patient stays, and demands from insurance companies and health organizations for measurable therapy outcomes may make it increasingly more difficult to address the long-range vocational needs of spinal cord injured patients in the rehabilitation hospital setting.

Occupational therapists can still play an important part in enhancing vocational outcomes for persons with spinal cord injuries, despite constraints imposed by the health care system. The history of occupational therapy in the work arena, as well as possible new strategies for addressing work issues during inpatient rehabilitation, will be discussed in the following section. 
The Role of the Occupational Therapist

The theory and philosophy of occupational therapy have historically supported vocational activity. The profession's interest in work-related issues is long-standing, but it has been sporadic and, at times, has stagnated (Cromwell, 1986; Harvey-Krefting, 1985). When the specialty of vocational rehabilitation counseling was born in the 1950's, it was considered by many occupational therapists to be better prepared to meet the vocational needs of persons with disabilities (Cromwell, 1985). There was also support, in the form of federal funding, for a stronger role by vocational rehabilitation counselors. According to Cromwell (1985), these were among the factors that have led to a "serious void in the area of job-readiness" (p. 17) in occupational therapy. There was less involvement of occupational therapists in work programs in the 1950's, 1960's and early 1970's than at any other time in the history of the profession (Hanson \& Walker, 1992).

Since the late 1970's, there has been much research and clinical practice growth in the area of work-hardening. Although the concept of work-hardening can trace its roots to post-war work-oriented programs in the early 1920's, it has evolved to apply primarily to the outpatient rehabilitation phase of returning to work after an industrial injury (Ellexson, 1989; King, 1992). Since ninety-five percent of the two most common causes of quadriplegia (traffic accidents and falls) occur during leisure activities, this population is not highly represented in the work-hardening arena (Yarkony, Roth, Meyer, Lovell, Heinemann, \& Betts, 1990).

The vocational needs of persons with spinal cord injury in an acute rehabilitation 
setting, where they will be receiving most of their occupational therapy, have received scant attention in the occupational therapy literature, possibly reflecting what was found by Pendleton (1990) to be a lack of attention paid to vocational issues during rehabilitation. In a study of the amount of time spent by occupational therapists in teaching independent living skills to patients in rehabilitation settings for whom such training was appropriate, Pendleton (1990) found that only .55 percent of treatment time was spent on vocational issues.

Spencer (1993) said that the role of occupational therapists, in meeting the prevocational needs of persons with spinal cord injury, consists of exploring feasible vocational areas of interest, determining salable skills, and providing opportunities to "learn functional levels" (p. 636). However, depending on the length of hospital stay and the level of function attained during rehabilitation, these goals may not be practical. Burke and Cassidy (1991) questioned of occupational therapists working in the present health care climate, "Do we have enough time to get to know the person, develop individually valued goals, elicit motivation and participation, and provide opportunities for individually meaningful successes?" (p. 174).

Considering that the vocational needs of the spinal cord injured person will of necessity take place in the rehabilitation facility, it is of concern that the rehabilitation stay is getting progressively shorter. In 1974, the typical hospital stay for a person with quadriplegia, was over five months, but by 1989 it was just over three months. The average stay in a rehabilitative hospital was about two and one-half months during the period from 1988 to 1991 (Ditunno \& Formal, 1994). Studies have found that persons 
with spinal cord injuries may not be ready to confront work issues soon after their injuries. A longitudinal study of vocational development after a severe spinal cord injury resulted in findings that indicated that the desire to work and the amount of realism and optimism about employment outcomes was not high enough to promote vocational development until six months after discharge from the rehabilitation hospital (Alfred, Fuhrer, \& Rossi, 1987). Combined with shorter hospital stays, these findings impact significantly on the role of occupational therapists in work-related activities. If patients are not ready to actively engage in vocational training before they are discharged, then past strategies for addressing work issues may not be adequate.

The role delineated by Kanellos (1985) may provide a new direction. As noted earlier, Kanellos (1985) contended that although the role of occupational therapists in vocational rehabilitation has diminished since the 1950 's, they still have a vital role in preparing a person with a spinal cord injury for eventual employment. She has suggested that the role should consist of providing ongoing functional and prevocational assessment; promoting opportunities for control, responsibility and problem-solving; increasing patient awareness of options; and encouraging the performance of job-related tasks. She added that in the prevocational stages, the occupational therapist is needed for "the expectation of productivity, the development of good work habits, the practice of personal hygiene ... the refinement of writing and other motor skills ... and the provision of other ancillary skills, such as driver training" (p. 732).

Hammell (1992) stressed the importance of achieving more than success in physical skills and activities of daily living. Some of her suggestions could assist in vocational 
development, including vocational planning and training, creative problem-solving, accessing community resources, negotiating community barriers, and social skills training. Contact with persons with similar injuries who have completed rehabilitation and can provide a long-term perspective was suggested in the literature so that patients know the possibilities for a satisfying future (Patterson, Miller-Perrin, McCormick, \& Hudson, 1993).

Because of the shorter hospital stays, the debate of when to approach work issues with a patient takes on more significance. Sullivan (1990) suggested that it is important to allow time for adaptation before attempting vocational adjustment, but that could mean that the patient would be discharged before vocational issues were addressed. From the time of the injury until six months after discharge from the hospital, the patient's vocational considerations may be secondary to survival and medical needs (Alfred et al., 1987). Kanellos (1985), on the other hand, encouraged immediate prevocational assessment with ongoing functional assessments and emphasized the importance of early long-range planning so that attention to vocational needs can gather momentum early and sustain that momentum throughout rehabilitation.

The pressures of third party payers also impact the role of occupational therapists. Since the Fall of 1983, when the Prospective Payment System (PPS) was enacted, external controls have been in force in the health care system, a process Baum (1985) referred to as industrialization. Under this new system, the author contended, it has been more cost effective for hospitals to shorten the length of stay and decrease the number of services provided. She saw the role of the occupational therapist working in acute 
rehabilitation as triage, that is, making plans for post-hospital rehabilitation. Howard (1991) noted that since the control of reimbursement policies has shifted to third-party payers, the use of the medical model of practice has been rewarded, that is the emphasis is on the disease rather than the person. Productivity and efficiency are high-priority goals and therapists must document their time in units of productivity (Howard, 1991). Given the constraints of the present health care system, occupational therapists must rethink how they will adhere to the principle of the profession to treat the whole person.

Burke and Cassidy (1991) noted a shift in the health care system to low-cost provision of care. Because of the high price of advanced technology, cost containment may lead to a lack of treatment technology (Howard, 1991), which could have an impact on treatment options for persons with high level spinal cord injuries.

Treatment planning must include consideration of how success will be defined. Burke and Cassidy (1991) contended that by their nature of being oriented to the individual, occupational therapists' goals are not statistically significant. The traditional definition of good rehabilitation, as success in meeting goals in physical skills, is problematic (Hammell, 1992). First, persons with high level injuries could be discounted as having no rehabilitation potential. Second, successful community reintegration is not dependent on physical skills alone; the rehabilitation goal should not only be the acquisition of skills, but should also include developing the motivation to use those skills (Trieshmann, 1980). A new gauge of success is necessary which accounts for the individual needs of the patients as well as the necessity for documentable goals.

An aspect of treatment planning that must not be overlooked is what work means to 
the individual and how that affects future employment. Velozo (1993) found current work assessment instruments to be limited by their lack of attention to what work means to the individual patient or client. Taylor (1974) said, "Therapists may not be communicating with patients what they perceive the goals of treatment to be or they may not be acting upon the feedback from patients regarding their wants and goals" (p. 29). A considerable amount of research has been conducted recently in occupational therapy on arriving at meaning through the use of personal narrative and narrative reasoning (Helfrich \& Kielhofner, 1994; Mattingly, 1991). The use of this method with patients in the rehabilitation hospital setting may be difficult in the current health care climate because the therapist may have a limited amount of time with each patient and may be required to justify that time in terms of functional goals.

\section{Frame of Reference}

The Model of Human Occupation has been used as a frame of reference to guide the exploration of the topic of the meaning of work (Kielhofner \& Burke, 1980). This model addresses an individual's motivation to work as a key component in performing the worker role. The importance of discovering the meaning attributed to occupation by clients has recently been added to this model.

The Model of Human Occupation describes the human being as an open system, comprised of three subsystems: volition, habituation, and performance. The volition subsystem, which was the area of concentration for this study, consists of innate and acquired urges to enact or initiate action (Kielhofner \& Burke, 1980). It comprises the 
"belief in the efficacy, importance and pleasure of action" (p. 577) and guides occupational behavior or performance. The volition subsystem, which includes personal causation (or self-efficacy), valued goals and interests, motivates action and exerts control over the other two subsystems.

The habituation subsystem, consisting of habits and roles, maintains action by organizing behavior into patterns or routines. The performance subsystem, which produces action, is composed of skills (Kielhofner \& Burke, 1980). The three subsystems interact with each other and with the individual's environment to initiate, produce and maintain action.

In an expansion of the concept of volition, Helfrich et al. (1994) added a narrative component which they said takes into account "the actual cognitive/emotional process by which persons view themselves and make decisions" (p. 316). They explained that a piece was missing from the volitional subsystem of the Model of Human Occupation. In the original model, volition was examined and defined according to traits which were considered to be "strong influences, if not determinants of behavior" (Helfrich et al., 1994, p. 313). In the recent research, however, the authors concluded that although traits are important aspects to consider in defining the structure of experience, the narrative component can explain the process of how experience influences volition.

Mattingly (1991) asserted that narrative reasoning, which uses storytelling and story creation to understand a particular individual's experience, is the primary form of reasoning used by occupational therapy clinicians. Narrative reasoning is an integral part of clinical practice, but it has only recently been identified and incorporated into models 
of practice. It is by integrating narrative reasoning into the treatment process that a total understanding of the patient's needs will be obtained, not just in terms of attaining specified goals, but in understanding that the experience of the process has important therapeutic value.

Narrative reasoning uses interview formats for storytelling. It is a method for conducting qualitative research.

\section{Qualitative Research}

Qualitative research, or naturalistic inquiry, was defined by DePoy and Gitlin (1994) and as being primarily inductive and theory generating; as discovering meaning through subjective understanding; and as focusing on complexity. They said that the researcher begins with the shared experiences of the participants and links concepts to each observation or datum. In this way the findings are grounded in a theoretical base.

There are several design options in naturalistic inquiry (DePoy \& Gitlin, 1994). The two that relate most closely to the current study are phenomenology and life history. The focus of phenomenological research is discovering the meaning attributed to daily experiences by allowing the information to come from the participants rather than from the researcher. The participant provides the interpretation and analysis of the meaning of experience. In a life history methodology, the series of life experiences and their meanings are studied from the participant's perspective. The analysis of the meaning of experience is primarily provided by the participant, but unlike the phenomenological method, it is not assumed that the meaning can only be understood by those who 
experience it.

The design of an interview guideline, which is a list of questions or issues to be explored, must be carefully developed in order to avoid excessive direction from the researcher and to "make sure that basically the same information is obtained from a number of people by covering the same material" (Patton, 1990, p. 283). The researcher must decide on the questions to ask, how to word each question, and finally how to ask the questions (Patton, 1990). Patton (1990) emphasized the importance of establishing rapport with the participants, while maintaining neutrality about the content of their answers. He added the following personal reflections on interviewing; "You must yourself believe that the thoughts and experiences of the people being interviewed are worth knowing. ... you must have the utmost respect for these persons who are willing to share with you some of their time to help you understand their world" (p. 357).

An important aspect of the research process is the credibility of the study. Krefting (1991) emphasized the importance of rigor in qualitative research in order to ensure the worth of the research endeavor. The terms reliability and validity, which are the criteria used to establish the credibility of quantitative studies may not be appropriate when applied to qualitative research (Krefting, 1991). Using Guba's model for the assessment of trustworthiness, Krefting details strategies to establish credibility, transferability, dependability, and confirmability of study findings. One strategy that is used to increase the credibility of qualitative research is member checking which consists of having participants check the "researcher's data, analytic categories, interpretations, and conclusions" (Krefting, 1991, p. 219). If the qualitative research of occupational 
therapists is to be taken seriously in an atmosphere dominated by quantitative studies, they must establish the trustworthiness of their work (Krefting, 1991).

\section{Summary of the Literature Review}

It is apparent from the literature that work is very important in society and that it is a valued goal of many people disabled by a spinal cord injury. The fact that most people with spinal cord injuries are not working is affected by external factors such as architectural barriers and societal attitudes, and such factors as amount of education and social support.

Some of the explanation for low employment rates is found in ineffective rehabilitation programs that make assumptions about the disabled individual's frame of mind, and potential for employment which may not be accurate. A variable that needs further study is the character of the individual's intrinsic motivation to work, within the context of his/her life story.

Occupational therapy has historically been associated with vocational issues, and although its history of practice in this area is sporadic, a considerable amount of research has been conducted in recent years regarding work hardening. There is, however, little found in the occupational therapy literature regarding the role of occupational therapy in addressing work issues with patients with spinal cord injuries during their inpatient rehabilitation hospital stay. Factors which could affect that role include the shortening length of hospital stays, reimbursement issues, and the survival rate of persons with high level cervical injuries. 
The Model of Human Occupation has been expanded to more adequately consider the meaning that work holds for each individual client. This is important whether the goal is to restore the functional ability to perform a worker role, or to find satisfaction through other meaningful activities. Recent research on the Model of Human Occupation centers on how a patient's perspective within the context of his/her whole life story influences and shapes the meaning attributed to experiences. In responding to what Helfrich and Kielhofner (1994) characterized as the fledgling level of research on meaning in occupational therapy, this study aimed to capture the meaning of work to men with spinal cord injuries within the context of a personal narration of their working life and to identify how to best meet the vocational needs of this population in an inpatient hospital setting.

Qualitative research begins with the shared experiences of the study participants and, through inductive reasoning, links concepts to data in an effort to discover meaning through subjective understanding. The phenomenological and life history methodologies rely on the participant to provide the meaning of their experience. An interview guideline is a list of questions or issues to be explored and follow-up questions are used to increase the depth of the data. Since models used to test the credibility of quantitative research are not applicable. new models are being developed to establish the trustworthiness of qualitative research.

Work is important and meaningful in the lives of persons with spinal cord injuries. Occupational therapists must explore their potential to enhance vocational outcomes for these patients and identify ways to provide activity that will have relevance not only in 
the rehabilitation environment, but especially in the patients' communities. 


\section{CHAPTER 3 \\ DESIGN AND METHODOLOGY}

\section{Purpose}

The purpose of this study was to explore how the meaning of work affects the future employment of men with spinal cord injury, and the implications of the findings for occupational therapists who work with this population in a rehabilitation hospital setting for patients with acute or subacute diagnostic conditions.

\section{Questions}

The questions explored in this study were:

1. What is the meaning of work for men with quadriplegia from a spinal cord injury?

2. Which factors are most associated with a successful return to work after a spinal cord injury?

3. What are the difficulties faced by men with quadriplegia from a spinal cord injury when they return to work?

4. What are the participants' perceptions of the effectiveness of occupational therapy in addressing work issues?

5. What recommendations do the participants have for occupational therapists who work with persons with spinal cord injuries in a hospital setting for patients with acute or subacute conditions? 
Sample

Five participants were chosen from a population of men over 22 years of age, who had a spinal cord injury at least three years ago which caused severe physical disability. They were not cognitively impaired, and they were treated by an occupational therapist during their rehabilitation after their injury. They were men who had worked full-time since their injury with no long periods of unemployment. Prospective participants were interviewed informally by telephone to determine whether they were qualified for the study.

Six prospective participants were contacted after being recommended by friends and colleagues of the researcher. Although all six men agreed to participate, one was unable to complete the interview and was therefore not included in the study. The participants constituted a sample of convenience. They ranged in age from 33 to 67 . They were disabled by spinal cord injuries from three to 35 years ago, that resulted in quadriplegia. Four of the five men were working full-time at the time of the interview. One man had retired ten years previously from a job he had held for 28 years since his injury.

\section{Study Design}

A naturalistic inquiry was undertaken using phenomenological and life history methodologies in order to elicit the participants' lived experiences concerning work. The field setting was chosen. 
Instrument

A loosely-structured interview was conducted with each participant at the participants' homes at a mutually agreed upon time. The interview guideline was formulated by the researcher based on findings of a review of the literature. (See Appendix A) The guideline questions were ordered chronologically to help participants account for particular periods of time (Sudman \& Sudman, 1982). The questions were divided into three groups: pre-injury education and work, injury and rehabilitation, and post-injury education and work. The questions were open-ended to elicit comprehensive answers and to limit the directing of participant responses by the researcher. Because they are often difficult to answer, questions asking directly for meaning or feelings were avoided (S. Murphy, personal communication, November, 1994). Final revisions to the guideline were made after review by the thesis advisor and faculty members. Probes (defined as follow-up questions) eliciting further detail or elaboration were used to enhance the depth and richness of the data (Patton, 1990). The interview was guided by this recommendation by Patton (1990): "In short, you must have the utmost respect for these persons who are willing to share with you some of their time to help you understand their world" (p. 357).

\section{Procedure}

The interviews were conducted over a three month period from June, 1994 to September, 1994. A quiet place in each participant's home was chosen to avoid distractions or inhibiting influences. Each participant was introduced to the study goals 
and outline of the interview and was asked to sign an agreement to be a participant in the study. (See Appendix B) Each interview was audio-taped; the researcher took minimal notes in order to facilitate a relaxed, conversational atmosphere. The audio tape recorder was tested prior to each interview and the recorder was placed as close as possible to each participant. Each interview lasted from one and one-half to two and one-half hours with each interview being completed in one session.

To enhance the validity of the study, several measures were taken. First, the researcher ensured that each question on the interview guideline was answered by all of the participants. If a question was not answered or if it seemed to be misunderstood by the participant, it was rephrased and asked again. A follow-up telephone interview was conducted using a structured questionnaire in order to complete demographic information, to further explore issues of interest to the researcher, and to clarify ambiguities from the original interview. (See Appendix C) A summary of each participant's original interview, plus the follow-up information, was mailed to the respective participants with a request to audit for errors or for misrepresentations. When the researcher contacted the participants by phone one week later, only one minor error was reported.

\section{Data Analysis}

The interview tapes were transcribed verbatim. The participants were identified as Mr. A through Mr. F to ensure confidentiality. Common experiences or similarities in responses were then compiled and categorized to answer the research questions, using the 
following method. Three copies of the transcripts were made. One copy was cut up, pasted on index cards, and sorted into groups to answer the research questions. Another copy was highlighted with different colored pens to identify themes within each question. A third copy of each interview was put into individual binders identified by each participant's designated name. This facilitated finding the individual responses of the participants on a particular topic. The emergent themes and patterns of the meaning of work and experiences in rehabilitation were analyzed for implications for inpatient rehabilitation occupational therapy. 


\section{CHAPTER 4}

\section{DATA AND RESULTS}

\section{Presentation of Data}

The data presented represents a summary of the information collected during the interview process. Individual case studies will be presented in four sections: Demographics, Pre-injury Education and Work History, Injury and Rehabilitation, and Post-injury Education and Work. Demographic information is summarized for all of the

participants in Table 1. Individual case study data are presented in the following section. Participants are identified by alphabet to protect their identity.

\section{Mr. A}

\section{Demographics}

Mr. A is a 44 year old married White male with a C5-6 spinal cord injury that resulted from a surfing accident in 1970, when he was 20 years old. He was married with one son when he was injured, but was divorced two years later and subsequently remarried. He lives with his wife in a home that they own. He has worked for a state tax agency for 19 years, as an auditor, supervisor, and district manager. He uses a manual wheelchair.

\section{Pre-injury Education and Work History}

Mr. A was a high school graduate who dropped out of a junior college after attending for one year. He grew up being told by family members that education is 
Table 1

Demographic information

\begin{tabular}{|c|c|c|c|c|c|}
\hline Participant & A & B & D & $\mathrm{E}$ & $\mathrm{F}$ \\
\hline Age & 44 & 39 & 43 & 33 & 67 \\
\hline Age at time of injury & 20 & 18 & 40 & 19 & 29 \\
\hline $\begin{array}{l}\text { Level of education } \\
\text { before injury }\end{array}$ & $\begin{array}{l}\text { High } \\
\text { school }\end{array}$ & $\begin{array}{l}\text { High } \\
\text { school }\end{array}$ & $\begin{array}{l}\text { High } \\
\text { school }\end{array}$ & $\begin{array}{l}\text { High } \\
\text { school }\end{array}$ & $\begin{array}{l}21 / 2 \text { yrs. } \\
\text { High } \\
\text { school }\end{array}$ \\
\hline $\begin{array}{l}\text { Number of years of } \\
\text { work before injury }\end{array}$ & 2 & 6 & 24 & 2 & 8 \\
\hline $\begin{array}{l}\text { Type of work before } \\
\text { injury }\end{array}$ & $\begin{array}{l}\text { Cement- } \\
\text { work/field } \\
\text { operator }\end{array}$ & $\begin{array}{l}\text { Butcher } \\
\text { Newspaper } \\
\text { worker }\end{array}$ & $\begin{array}{l}\text { Bricklayer } \\
\text { Business } \\
\text { owner }\end{array}$ & $\begin{array}{l}\text { Maintenance } \\
\text { Unskilled }\end{array}$ & $\begin{array}{l}\text { Con- } \\
\text { struction } \\
\text { Plumbing }\end{array}$ \\
\hline Level of injury & C5-6 & C4 & $\begin{array}{l}\text { Incomplete } \\
\text { C6-7 }\end{array}$ & $\begin{array}{l}\text { Incomplete } \\
\text { C4-5 }\end{array}$ & C5-6 \\
\hline $\begin{array}{l}\text { Education since } \\
\text { injury }\end{array}$ & $\begin{array}{l}\text { AA } \\
\text { BA }\end{array}$ & MBA & None & $\begin{array}{l}3 \text { yrs. } \\
\text { College }\end{array}$ & $\begin{array}{l}\text { On the } \\
\text { job }\end{array}$ \\
\hline $\begin{array}{l}\text { Type of work since } \\
\text { injury }\end{array}$ & Accounting & $\begin{array}{l}\text { Computer } \\
\text { database } \\
\text { consultant }\end{array}$ & $\begin{array}{l}\text { Brick } \\
\text { laying } \\
\text { consultant } \\
\text { Bus. owner }\end{array}$ & $\begin{array}{l}\text { Computer } \\
\text { programmer }\end{array}$ & $\begin{array}{l}\text { Shop } \\
\text { supervisor } \\
\text { Manager }\end{array}$ \\
\hline $\begin{array}{l}\text { Number of years } \\
\text { between injury and } \\
\text { first work }\end{array}$ & $\begin{array}{l}41 / 2 \text { yrs. } \\
\text { ( } 4 \text { yrs. } \\
\text { college) }\end{array}$ & $\begin{array}{c}3 \text { mos. } \\
\text { (part time) }\end{array}$ & 0 & $11 / 2$ yrs. & $1 \mathrm{yr}$. \\
\hline $\begin{array}{l}\text { Number of years } \\
\text { worked since injury }\end{array}$ & 19 & 20 & 3 & $111 / 2$ & 24 \\
\hline Working now? & Yes & Yes & Yes & Yes & $\begin{array}{c}\text { Retired } \\
1985\end{array}$ \\
\hline $\begin{array}{l}\text { Marital status } \\
\text { pre injury * }\end{array}$ & $\mathbf{M}$ & $\mathbf{S}$ & D & $\mathbf{M}$ & $\mathbf{M}$ \\
\hline Marital status now & $\mathrm{D} / \mathrm{Re}-\mathrm{M}$ & $\mathbf{S}$ & $\mathrm{D} / \mathrm{Re}-\mathrm{M}$ & $\mathrm{D}$ & $\mathbf{M}$ \\
\hline
\end{tabular}

* $\mathrm{M}=$ Married, $\mathrm{S}=$ Single, $\mathrm{D}=$ Divorced, $\mathrm{Re}-\mathrm{M}=\mathrm{Re}$-married 
important, but with none of his family having gone to college, he lacked role models for motivation. His teachers always said he could do better than he did, but he said he "cruised through, doing the least amount possible." He had plans to pursue a college degrec, but at the time he was not motivated to finish.

Before he was injured, Mr. A had been working full-time for two years doing various jobs at an oil company research plant. His job in concrete labor work took place outdoors and was physical; however, most of his work was as an "operator" which was less physical and entailed taking and reporting readings every hour and taking samples.

He said he enjoyed his work, although he feels now that he would have been bored with it over time. He described it as being labor intensive and that once the job was learned, it required doing same thing over and over. He assumed at the time that, like his father and uncles, he would work at one company for his entire life; he considered it a good job with a secure company.

Mr. A said that in growing up in a working class neighborhood, with both parents working, he considered work as "what you had to do." He felt it was something he had to do to survive; he felt that he had to do the best he could at whatever job he could find.

He worked a different eight-hour shift each week. On a typical day shift, he was at work at 6:00 a.m. and got off at 2:00 p.m. with no lunch break. Three or four days a week, he went surfing either after his day shift or before his swing shift.

\section{Injury and Rehabilitation}

Mr. A often went surfing after work and often alone, but on the day of his injury, in 1970 , he went with a friend from work. A wave broke over his board, pulling the board 
out from under him and sending him upside down, head first into the sand, breaking his fifth and sixth cervical vertebrae. His friend saw him face down in the water and pulled him out.

Mr. A was not told immediately of the extent of his injury because he was not expected to survive. When he learned of the seriousness of his injury, after a week in the hospital, he continued to believe he would get return of function since he was being sent to rehabilitation. He spent about six months in rehabilitation; the first six weeks were spent in traction, then he wore a brace for another six weeks.

Mr. A described his stay in rehabilitation as "like being in the army." From 8:00 a.m. until 4:00 p.m., he went back and forth from occupational therapy to physical therapy. He said it is a fond memory because he was doing something and seemed to have some focus."

Mr. A said that in the beginning of his rehabilitation, he felt that he was being pushed too hard, but after a while it became part of his daily activity and he said, "In a way, it probably was like going to work." He described his appreciation for a particular night shift attendant in the hospital who intuitively knew how far to push his patients in insisting on their independence. He experienced many attendants as well as family members of other patients who helped the patients too much, not allowing them to determine what they could do for themselves.

Mr. A advised future therapists to look beyond the injury and to help the injured person focus on what he or she wants to do or what he or she wants out of life. He said, "If they tend to dwell on what could have been, try to steer them into what they can do 
and develop that."

An injured person, he said, cannot limit his or her perspective. He said, "You have to try to go beyond what people say you can do, and if you fail, you fail." Mr. A said it was helpful when previously injured people came back to the rehabilitation hospital for an outpatient visit because he was able to see that disabled people "were out there in the world."

Mr. A does not remember talking with family members during his hospitalization about his feelings concerning work since he tended to "keep a lot of stuff just to myself." He said that he was dealing more with the practical issues than the emotional ones because he just wanted to move on and to figure out what he could do with what he had left. Mr. A said he does not feel that there is a set time that would be right for all patients to discuss work issues after an injury, but he does feel that at some point a patient has to be told to "get over it" and stop thinking about what they cannot do.

He said he thinks, however, that he probably talked with occupational therapists a lot because they helped him learn job skills such as typing, writing, and telephone skills with the idea that he would be going to an office job at the oil company. They also helped him with activities of daily living to increase his independence and prepare him for the work world. He spoke with the vocational rehabilitation counselors about work, but he declined to speak with the staff psychologists.

Mr. A's superiors at the oil company planned to hire him back in an office job to replace his former physically demanding job. Mr. A said that knowing a job was waiting for him was a motivating factor during rehabilitation, but when Mr. A was scheduled to 
be discharged from the hospital, the company told him that they were unable to find a job for him and he was not to be hired back. He said that although the news was devastating to him, he does not remember thinking that there was nothing he could do. He described it as "more of a wonderment of what I would do" and that he had to "refocus."

\section{Post-injury Education and Work}

It was at this point that Mr. A realized that he needed an education in an area that would use his mental capabilities. He went through testing at the Department of Rehabilitation to determine his aptitude and was told that he could do professional or semi-professional work. He considered several options, such as architecture and history, before discovering that he liked accounting.

Mr. A found that it was easier to focus on studying than it had been when he was younger. He was able to go to school full-time because he received disability payments from the oil company as well as money from the Department of Rehabilitation. He had to drop out for one semester to have bladder surgery, but he was so motivated to graduate that he took summer classes and increased his course load.

Mr. A had to "fight with" the Department of Rehabilitation to continue receiving pay for his education past achieving an AA degree. At that point they felt he was qualified to start work as a bookkeeper, but he persisted and completed his degree in accounting within four years. He said that he could have done something related to his high school education but, he said, "I felt I reached beyond that."

Mr. A said he feels that his motivation was due in part to his optimism and the fact that he never dwelled on how things should have been. He said, "I figured out at one 
point that the world can go on with or without me and I'd just as soon be with it."

Mr. A encountered a financial disincentive to excel at work when he was offered a paid internship by the IRS when he was in school. He was unable to accept it because his social security benefits would have been discontinued and he would not have been able to support his family on the intern pay. Mr. A was motivated to get back to work partly because he had a wife and son to support and partly to be as economically independent as possible. He said he did not like collecting social security.

It took Mr. A about six months of job hunting before he was hired by a state tax agency as an auditor. He said he feels that his difficulty finding a job was, at least in part, due to his disability as well as to his inexperience in being interviewed.

He said he feels he was hired by the tax agency partly as an affirmative action measure, but he said that he was treated fairly from the beginning and that he has the respect of his peers not only for the quality of his work, but also for what he has accomplished, given his disability.

Mr. A loves working and said that when he returned to work, he felt like a productive member of society again. He added that whether one is disabled or not, one must be satisfied in one's work to be satisfied in life. To be satisfying, he said, work must be challenging.

Mr. A's job now is manager of the district office of the tax agency. He has forty people working for him. He said that although there are frustrations, he finds that he is never bored because there is always something coming up with which he must deal. He said that it can be "emotionally wrenching," but that there is satisfaction when "you've 
dealt with it and moved on to the next."

Mr. A identified several difficulties in returning to work. Besides fatiguing easily at first, he wondered if he would be accepted, if he would move up in an organization, how he would be treated and what others' reactions would be toward him. The lack of wheelchair access to the offices of some of his audit clients was a problem at first, but the tax board made accommodations to meet his needs.

In his job now as a supervisor, Mr. A encounters difficulties with travel requirements. He is unable to stay overnight in a hotel without attendant care, so unless his wife (who also works full-time) is available to accompany him, he must travel long round trips in one day. Mr. A has never had attendant care, but realizes that eventually he will have to "deal with that."

Mr. A said he feels that his co-workers accept him and at a certain point they do not notice his disability any more. He does not feel prejudged by them. He does encounter some stereotyping by people who do not know him, which becomes apparent when people

express surprise that he has a job. He said that when that happens, he feels superior because he is working and making a decent income.

Mr. A said he sees no reason why people who are no more severely injured than he should not be working. He said he feels that it is "a matter of motivation to figure out what they can do with their lives and pursue it." He said that the difference between being motivated to work and not motivated is whether you dwell on the past.

Mr. A takes satisfaction in his work knowing that he is contributing something and 
he also has pride that he has been able to work his way up with a disability and gain the respect of all the people with whom he works. He said he feels that the difference in the meaning that work holds for him now, compared to before his injury, is more a matter of age than disability. He said that work takes on new meaning after an injury in that it is a good "time occupier."

His future plans or dreams are to work as high in the organization as he can and, he said jokingly, "to retire rich." He is concerned that he will not be able physically to work beyond age $\mathbf{5 5}$ so he said his focus now is thinking about how he can keep working.

Asked how he makes sense of the changes in his life, Mr. A said that he does not know if he tries. He said he sees it as something over which he has no control, but maybe "if there is something out there where it's meant to be, then I am here to show something because I am doing pretty well. ... Other than that, it's only to say, 'Gosh, it would be nice not to be disabled'."

Mr. B

\section{Demographics}

Mr. B is a 40 year old single White male with a C4 spinal cord injury that resulted from a diving accident when he was 18 years old. He has never been married. He lives in a home that he owns and he has a full-time attendant. He has worked full-time as a self-employed computer database consultant for the past seven years. He uses an electric wheelchair. 


\section{Pre-injury Education and Work History}

Mr. B graduated from high school with plans of joining the fire department. He said that in high school, if he wanted a grade, he could get it and if he did not care, he did not [get the grade]. He did not intend to go to college, but he would have been required to attend training and to take an examination for acceptance into the fire department.

Mr. B had his first job when he was 12 years old and held three jobs at the time of his accident. He said he grew up in a blue collar family with the understanding that nothing is free and that "you have to work for it to get it." He remembers that it was important to him to do a good job and to have pride in his work. He had chosen fire fighting as his future career because of the risk involved and because it would satisfy his "need to be athletic and to maintain a certain physical condition."

Mr. B's typical weekday before his injury began with work at a butcher shop at 5:00 AM. He worked two hours, then returned home to pick up his mother to take her to work on his way to school. After school he went to another job, taking time during his shift to pick up and deliver his mother to her home. He finished work at 7:00 PM on weekdays and worked all day Saturday.

He said that he was motivated to work hard for the "fruits of working"; when he was sixteen years old, he bought a car and, he said, "Car equals girls." He said he always got up early and continues to be an early riser even when he has no work to do.

Injury and Rehabilitation

Mr. B was injured on a summer day at a California river. He was standing on a bridge, ready to dive into the river when friends yelled that it was too shallow, but he 
assured them that he had checked it two weeks earlier. He had checked it, but the water level had dropped, so when he dove off, he broke his neck. His first thought was that he was an "idiot" for killing himself. That is all he remembers until he awakened unable to talk or move and was connected to a ventilator.

Although at the time Mr. B said that he wanted to die, he now believes that he "never authentically wanted to die, never felt a reason to leave." He explained that, More than anything else was everything that I understood to be true wasn't true any more. My reality had changed and it was just like being bopped over the head and being dazed and trying to gather your thoughts and go on.

He spent 13 months in the hospital, most of which time he was on a respirator. $\mathrm{He}$ had eight codes blue and one coma during that time. He said that work was the least of his worries at the time of his injury; initially he was more concerned about his ability to have sex, to live and to enjoy life.

Mr. B said, "My fundamental characteristics of who I am were all there before I broke my neck. That's what brought me through and gave me strength." Mr. B described his process of coping with his injury, I understood when I broke my neck that I victimized the two other people [his parents], and I realized that these people had been injured and that they couldn't hold it, they couldn't touch it, they couldn't see it as I do. It wasn't their responsibility to get through it, but it was mine and it was up to me not to be negative ... I lessened their pain because they can't do anything about the hopes and the losses for their child. 
Mr. B said he feels that while he was in the hospital he dealt with his injury and that he "will never have to deal with it again." He said, "There is no pain, there is no agony. I don't wake up in the morning wondering why. The why question was never important for me." He described himself as a basically happy person who has always enjoyed life.

He said he doesn't like miserable people and has no patience for people who feel sorry for themselves. One frustration for him still is not being able to do things for other people since he is so often in the position of needing things done for him.

While in the hospital, Mr. B reported that he was told that he could do nothing but watch TV and stay at home the rest of his life. He said that the rehabilitation staff was unprepared to work with a patient with such a high level injury since it was only recently that technology existed that allowed survival. The biggest problem, he said, was not getting information; he said he wanted the facts rather than hearing, "Well, maybe you'll walk some day."

Mr. B said that although he was in the hospital a long time, he feels that his rehabilitation was non-existent. It was "toysy" rather than practical or applicable. Of his time in rehabilitation, he remembered that he "smoked plenty of pot, drank plenty, and had lots of Jack Daniels." He said that he would have preferred a shorter rehabilitation time so that he could "get moving."

When asked when would have been an appropriate time for a therapist to bring up the issue of work, he said that for him, it would have been immediately, to let him know the alternatives. He said that a disabled person needs to be exposed to the alternatives in 
order to make choices.

Mr. B had no use of his arms while he was in the hospital. It was not until over a year after his injury that he was able to start lifting his arms. About his experience with occupational therapy, Mr. B said,

It wasn't bad. I went to OT and they had their little toys. It was like being in a little play shop. I spent my time. I'm a people person, so what was bad?

Nothing. I went and had fun with the people.

He said he feels that the occupational therapists were unable to provide him with meaningful activity because he was so limited and the options were so narrow. He said that they were just learning themselves how to work with a person with a high spinal cord injury. He said he feels that, rather than forcing everyone into a mold, the therapists should funnel a person in a direction that he or she feels comfortable with and then let them go. He said that he needed his freedom to "realize what my freedom was."

He said he feels that much of OT was unrealistic or impractical. When he was first in the hospital, the occupational therapists wanted to "try out every god damn new thing." He went on,

Who wants to sit there (with their arms in a trapeze) and take fifty minutes to eat their god damned breakfast? They're not realistic. If you're going to be competitive in the real world, you've got to do competitive things and you've got to do them on time just like everybody else.

For example, he was taught range of motion exercises, but with a busy work schedule and with the long time that it takes him to do his activities of daily living, he has no time 
for morning range of motion exercises.

His advice to occupational therapists was to have expectations, and that although everyone must go through the grieving process, after such an injury it is the therapist's job not to make it easy for them to be a cripple. He said that when he was first injured he was blinded by physical and mental pain. He said he equates the mental pain with death and although he had to go through the grieving process, he was grateful that his friends didn't baby him. They had expectations of him and didn't treat him "like [he] was worthless."

\section{Post-injury Education and Work}

When he was discharged from the hospital, Mr. B went to live with his parents. He said that the hospital staff had trained his parents to believe that he would be at home the rest of his life, so he said he had to fight his parents constantly to do things by himself, such as riding BART ( Bay Area Rapid Transit). He said he had to test his confidence and despite the physical obstacles, he persisted.

During this time he got into what he referred to as the commodities business. He said he had two alternatives; live on $\$ 300$ a month and do nothing, or greatly increase his salary and do a lot. All of his business was done over the phone and with the money he earned, he was able to go camping and traveling and to museums, movies, and plays. He said that he spent nine years having fun and saving money.

At age 25, Mr. B returned to school, quitting the commodities business because he became disgusted with the people with whom he did business and because he was not feeling a sense of accomplishment or a feeling of helping people. He had also begun 
reading technical magazines and realized that there might be opportunities for him to work with computers.

Mr. B said he wishes he had started getting at education earlier but he had no role models to show him his options. He did not know whether he could really work, but he did take correspondence courses. He started out taking courses in audio engineering but realized he would be unable, physically, to operate the equipment. He enrolled at a junior college in a computer science class and eventually earned a Bachelor's degree with honors in computer information systems and finance. He went on to earn a Master's of Business Administration. He said that he feels education is the key to "getting out from wherever you are." He has applied for a Ph.D. program at an elite business school.

Mr. B expressed strong feelings about the government's financial disincentives to work. Because his injury is so high level, Mr. B needs 24 hour attendant care and his supplies cost $\$ 350$ to $\$ 400$ per month.. If he makes over $\$ 300$ at a job, he will lose his Social Security payments which cover his attendant care and a rent subsidy. He said he feels that the system is set up in such a way as to discourage work; it was established before people with high level injuries were surviving and the system has not reflected that change.

He said that money was not a major motivation for him to pursuc a career in computers. Rather, he said, it is the reward of seeing a job well done. He said he knew that a job like answering the phone would not be fulfilling. He always knew he could think, but now, he said, he has turned his physical strength into mental strength.

His first job after starting school was tutoring at the junior college. Now he works 
mostly at home, but also goes into corporation offices to work. To avoid having his benefits reduced, Mr. B uses a barter system with many of his clients. Difficulties about returning to work included working out attendant care and getting paid less due to the cash nature of his payment. He is, however, considering accepting an offer of a full-time job in which he would work primarily at home, going to the office two days a week. Although the salary would be good, he is not sure he will be able to cover his expenses without his benefits.

Mr. B reported that he gets pleasure at work from completing a task and from "the quality you put into it." He said he just enjoys working and having a task to do. He said he feels he has a positive relationship with his co-workers and although people generally see the wheelchair first, and as they get to know him, the wheelchair disappears. Mostly, he said, his co-workers' reaction to him is based on their reliance on him to give them accurate information.

Mr. B would like to work in a corporate environment, so he is considering accepting a full-time job in which he would work at home three days and at a corporate office two days.

As for making sense of the changes in his life, he said he has accepted it and he does not have to deal with it again. He said he does not look for a meaning of life; he just experiences it and enjoys it. He explained, I still miss the earth under my feet. I always felt, since I was a child, I was part of the planet. I feel separated. I will never have that feeling again, but I try to come as close to it as I can. 
Mr. D

\section{Demographics}

Mr. D is a 43 year old Black male with a C6-7 spinal cord injury that resulted from a physical assault by his son. At the time of his injury, he was dating the woman from whom he had been divorced 12 years earlier and they have subsequently remarried. He lives with his wife and mother-in-law (who is also disabled) in a home that they own. He arranges jobs through his bricklaying and concrete business and also acts as a consultant for other contractors. He uses an electric wheelchair.

\section{Pre-injury Education and Work History}

Mr. D is a high school graduate who wishes he had had more education. He said that although his parents stressed the importance of education, he didn't care about college at the time. His father told him that there are two things that people cannot take away: a trade and an education. Mr. D had his trade by the time he graduated from high school and since he figured he was not good enough for college, he chose to remain with his trade.

He always wanted to be a bricklayer like his father and as early as fourteen years old, Mr. D was helping his father pump concrete. He said he always worked with his hands. He learned that in order to make it in life he had to go out and work for himself because "nobody's going to hand you nothing." He felt that as a Black man, he had to work extra hard to "accomplish the same thing as the other person."

What he remembers most as being important about his work was the pride in his art and knowing that he was making something that would last forever. The money was also 
important as was the satisfaction of being the only person qualified to do a particular job. He became a bricklayer's apprentice at age 17, and a journeyman bricklayer when he was 20 years old. During this time, he worked many evenings and nights doing bricklaying jobs on the side in order to save money. He remembers enjoying work so much that he "hardly went back home."

After being a journeyman for two or three years, he started his own company, employing up to ten men with as many as 20 jobs at one time. He was planning to retire in five years with a lot of money. He said he planned to have his son or someone else run the business so that he could travel or go fishing.

As his business grew and he hired more employees, the stress increased and Mr. D was troubled by high blood pressure. At the time of his injury, he had down-sized his business to cut down on his expenses and to relieve some of the stress; he was beginning to enjoy his work again.

With a typical work day beginning upon arising at 4:30 a.m., Mr. D began work at 6:00 a.m. with making the day's schedule on the computer. He would then meet with his employees to determine who would go to each job. He saved preferred jobs for himself. He then worked at job sites all day and in the evening. He often worked into the night on machinery repair and maintenance.

\section{Injury and Rehabilitation}

In 1991, Mr. D was on a job site where his son worked as his employee. His son became angry with him, grabbed him and twisted him causing Mr. D's neck to snap. Mr. D reported that he was told that his son kicked him after Mr. D had fallen, but he does 
not remember this. Mr. D was told that he died on the table at the hospital and that he would be a vegetable.

Mr. D had no movement at first and said if he had remained paralyzed, he probably would have considered suicide. He said he was unable to feed himself and had to be rolled over every two or three hours in bed.

Mr. D still had almost no movement of his arms and legs during the time that he was receiving rehabilitation and said that he was experiencing pain all during therapy. From the time of his early hospitalization, he was called daily by family members with questions concerning the bricklaying business. He said it was a nightmare because his sons were only seventeen and eighteen years old and too young to take on such a big responsibility. He said that he felt he had to "deal with it" to pay the bills and to keep from losing his house.

Mr. D did not talk about his feelings about work with anyone because he wanted to "keep people from crying." He said work was not really discussed with his therapists; "they mostly focused on, ' [Mr. D], see if you can feed yourself or see if you can brush your teeth'." He said he was in "too bad of shape" to think about holding a job.

Mr. D said that a typical day in rehabilitation consisted of eating breakfast, getting bathed, and watching a lot of TV (which he said is the only thing that kept him sane). He started therapy at 9:30, but when he got his electric wheelchair, he avoided many of his therapy sessions. Therapy focused more on activities of daily living than on work issues. He described his experience with occupational therapy as,

Oh, that room. I didn't like that room. I had to go because I was part of the 
program, but I couldn't see what they were doing for me. My hands didn't work, they want to teach me how to write... I just couldn't understand what they were doing.

Mr. D said he understands now that it was a starting point, but at the time he said, he didn't understand that it was exercise. He also felt at the time that he didn't need adaptive equipment (e.g. for writing) because he was convinced he would get better.

Mr. D said that to be a good occupational therapist, one should love his/her job, respect their patients and never show any prejudice. One should give patients hope and reassurance and state the goals of therapy clearly as well as the reasons for doing particular activities. He also said that an occupational therapist should encourage patients to learn to sign their names so that they do not have to have someone else sign for them.

Mr. D said that he feels it would have been helpful to him if someone with a spinal cord injury had come to talk with him to let him know what to expect. He said that he would have listened to someone else who was hurt, especially if that person was Black.

Mr. D has had no vocational program since his injury because he said they would have to teach him something new; he wants to try to do something he already knows (bricklaying). The one benefit he said he could have received from a vocational program would be learning how to drive so that he would not be dependent on others for transportation. He is currently remodeling a truck that he will be able to drive independently, as long as someone can help with transfer mobility.

Mr. D said that to cope with his situation, he decided in the hospital to "go day by 
day." He used his sense of humor, particularly with the nurses, and he said he cried at night to "get out the hurt feelings."

Post-injury Education and Work

Mr. D has not had any further formal education since his injury. When Mr. D first returned home, he worked in bed and answered the telephone with his tongue. He took jobs over the phone, spoke into a recorder and then his wife wrote the job up from the tape. He would then hire people to go do the job. He continues to be called by former customers to be a consultant for concrete and bricklaying jobs. To go to the job sites, he either takes a city bus or has a friend drive him.

He said his work schedule now is similar to his pre-injury schedule although he is not able to get up as early in the morning as he did previously since his wife must bathe him and get him into his wheelchair after she returns from her night job. Once in his wheelchair, however, Mr. D begins answering phone calls, goes to job sites, or talks with friends. He said he works hard and stays out late so that when he returns home at night he is able to sleep.

The most difficult part about returning to work for Mr. D was not knowing whether his physical condition would improve. He also had to cope with kidney and bladder infections and pain. At first he had to take someone with him to put a catheter in every four hours. As he put it, "Oh, I could tell you stories that's happened to me," such as sliding down on the gas peddle of his truck on the freeway on his way to work after forgetting to put on his seat belt.

Mr. D said that the difference between work at the present time and work before the 
injury, is that he has so much less money and less control. He said that he used to tell twenty or thirty people what to do and that to take orders is hard. He said that he has had moments where he has "put his disability in front of [his] authority" in ways that he never would have before his injury.

Mr. D is motivated to work by the need for money and also by the fear that if he stops, he will get lazy and have a hard time getting back up. He tells himself, "You've got to get up because if you stay here too long, you're going to like it." He said he considers his motivation to work at the present time as being different from before because it is more of a challenge.

He also said, on the other hand, he feels that work is less important than it was before his injury and that his outlook on life has changed. He said he has realized that he does not need as much money to survive as he thought he did. He receives satisfaction from being needed on the job. He said he really works hard and has a lot of responsibility; he just doesn't work with his hands.

Mr. D also receives satisfaction from teaching someone who has never touched concrete to do a job. He said he has always taught his craft and that he continues to do so. He said he gets more satisfaction now from his work because he is able to finish something with someone else's hands. He described his feelings as, "I remember the first time I got paid; they actually paid me for my mind. I said, shoot, this might work." He said he gets a lot of respect from others for what he is doing. "Working, making a living, and keeping things up gives me self-esteem and self-respect."

Mr. D said that although everybody says there is a reason for his injury, he cannot 
make any sense of it; to him, it does not make any sense. He still holds out the hope that he will walk again some day. He plans to go to a rehabilitation program where he hopes to learn how to drive and to walk.

\section{Mr. E}

\section{Demographics}

Mr. E is a 33 year old White male with an incomplete C4-5 spinal cord injury that occurred while he was playing football when he was 19 years old. He was married at the time but was separated two days after leaving the hospital, and divorced six months after that. He has been single since and now lives in an apartment with his mother and his niece. He works full-time at a large science laboratory as a computer programmer. He uses an electric wheelchair.

\section{Pre-injury Education and Work History}

Mr. E is a high school graduate who worked in the Air Force for a year in aircraft maintenance after graduating from high school. Although the importance of education had been stressed to Mr. E as he grew up, and he felt it was important generally, he said he did not concentrate on it and he was not focused at the time. Two months before his injury, he had begun a vocational retraining program to be an electronic technician, a job which entails fixing computers.

Mr. E said he feels that growing up on a ranch doing chores every morning instilled some of his values about work which he now holds. He learned that work is important, that you must work to excel, and that work can be satisfying in itself. He does not 
remember enjoying work; it was something to do to make money and pay the bills. He described his typical work day as beginning by putting on old grubby clothes, going to work, doing whatever he was told to do, going home, and dreading having to go back to work.

He said it was different when he started his electronics training. He described it as being where he wanted to be; he was starting to enjoy work a little bit more and felt he was on his way to a career.

Injury and Rehabilitation

In 1981, when he was 19 years old, Mr. E was playing tackle football with friends, as he had for years, when he ran with the ball and hit another player "the wrong way," dislocating his neck at C4-5. A few hours later, when a doctor told him he had an $80 \%$ chance of survival, he made a decision to accept the way things were and to move on. He said he feels that this decision was a real plus for him because he was able to "fight this thing out" from the beginning. His decision was to "deal with it day by day." He said this attitude may have come from his "type A, on the go, independent personality."

Mr. E spent five months in the hospital and another two and one half months at home in what he refers to as "post-hospital recovery." For the first two months of his rehabilitation, Mr. E was in a "Roto Bed" on an iron lung. He remained in traction for six weeks. After two months, he was able to get up, but only for three or four hours a day. The emphasis of his rehabilitation was on arm mobility. His only upper extremity movement was in one shoulder.

Although he had been interested in computers since he was sixteen, Mr. E was not 
sure what he would do for work since his chosen career of electronic technician required finger dexterity. After three months in the hospital, when he was "up and about," Mr. E's family brought him a computer which he considers his first vocational training after his injury. He did not talk about his fears of not being able to work because he felt he had to be strong for his family.

Mr. E also said that because of his many medical problems he was not thinking very much about his long-term goals. He was in an iron lung for two months, he had a bleeding ulcer and he was "Code Blue" three times. Also, a month before his release from the hospital, his father died. Mr. E said he feels that it would have been inappropriate for therapists to talk about work issues with him in the hospital since his condition was so limited that work was not an issue.

The focus of therapy was on enabling him to survive at home with help. He said the timing of bringing up the issue of work is very personal and that a therapist must be patient and not force someone to make "critical lifestyle changes." He said that for him, work did not become an important issue until he was out of the hospital and began having return of function.

The only thing Mr. E remembers about his occupational therapy was trying to figure out how to hold a pencil so that he could write. He said it was very frustrating for the occupational therapist. He said that is all he can remember except that occupational therapy was “just something I was asked to do, so I did it." He did not receive much occupational therapy because he was bedridden for much of the time while in the hospital and was released shortly after being able to get out of bed. 
He said that occupational therapy was probably worthwhile because it made him begin "to think about that kind of stuff." He described the therapists and doctors as "pushing, pushing, pushing" and said that not everyone is ready to accept his or her condition. He said he probably did not enjoy occupational therapy because it was a lot of work doing things that he did before the accident without thinking about them.

Mr. E said that an occupational therapist must let patients know that there are people who have gone through what they are experiencing and who are now enjoying life. He said therapists must relay the message that life goes on and that "life is what you make it". Mr. E said he feels that it was very beneficial for him to talk with former spinal cord injured patients who visited the hospital while Mr. E was first injured. He said they would talk about staying up and only getting about six hours of sleep a night whereas at the time, that was the amount of time that Mr. E was able to be up during the day. He said "it let me see that things were going to get better." He also said that he feels an obligation to share his experience with other people.

Mr. E said he wishes it were possible to bottle his enthusiasm to give to everyone so that they could view their disability as an opportunity. He said his disability is ten percent physical and ninety percent mental, so although the ten percent is a big part, it is only a small percent of the "overall aspect of life."

\section{Post-injury Education and Work}

When he first left the hospital, Mr. E lived at the family ranch with his mother and brother. For the first six months he was dependent for most activities of daily living, but after negative experiences with attendants, he began doing more for himself. He was 
encouraged at each step by friends who gave him positive feedback and who said they were inspired by him. After going home from the hospital, Mr. E was visited by a counselor from the Department of Rehabilitation who suggested that he go to school, so eight months after his release, he began taking computer classes.

Two years after his injury, Mr. E had completed three semesters of college when he got a summer job programming computers for a roofing company. Mr. E realized that he enjoyed working more than going to school so he stayed in that job for four years. He went back to college for one year and then began working at a science laboratory where he has been a computer programmer for the past seven years.

When he first started working, it was Mr. E's first time on his own since his injury. His worries were of a physical nature, such as how he would take a shower and go to the bathroom. He said he never really worried about whether he could do the job. Mr. E contended that transportation is an important aspect of returning to work and that is should be stressed during rehabilitation. He stressed that mobility in the community is as important as mobility around the house.

A typical work day now involves getting up, showering, dressing and eating breakfast, all independently. When he arrives at work at about 8:30 a.m., he checks the computer systems, fixes any problems, then starts working on new development. He spends most of his time in his office but also attends regular meetings. He leaves work at about 4:00 p.m.

In explaining his success at work, he said, "I've always been kind of one of those opportunistic people. I'm very active and I make things happen." He said once he got 
out and started working, it has been "up, up, up." Mr. E explained his feelings about his motivation in work and in life.

It's very rewarding to go to work, find a problem and be able to fix it and have it work. I guess in a lot of ways, that's how I approach my life. I see a problem and fix it. I don't sit there and bitch about it, I fix it ... I take an active stance in my life.

He said of his physical condition, "I keep wanting to go further, but it's not something that I have to be up and walking before I feel like I am a total human being again."

Mr. E enjoys his job and has been surprised to find that his co-workers have been very accepting of him. He said he feels he is treated as a peer and not as a handicapped person. He likes the fact that he receives no special treatment; his co-workers expect him to do his job and they depend on him. For Mr. E, work is the reason he gets out of bed in the morning. It is something he looks forward to and which he described as his driving force. His whole life is centered around his job. He finds the challenge of problemsolving at work very rewarding.

Before his injury, work had been something that Mr. E did to pay his bills, but now he cannot wait to get up in the morning to go to his job. He finds it very challenging and very rewarding that he has control over what he does. He appreciates that he has been given professional freedom that he described as the flexibility to do things the way he wants to do them. He said that the meaning of work has changed for him more because he has grown up and matured than because of his disability. 
As for making sense of his disability, Mr. E said he feels lucky to have had two lives: one before the accident and one after. He explained it as "kind of a break in service, if you will, to start over and try again ... It's given me an opportunity to change the way I was." He said he feels it has made him tough so that little things do not bother him. He said his life is "a lot better now than it was before in so many ways."

As for his future plans, Mr. E said he feels that his career is on track and that what he would like for his future is a romantic relationship with a woman.

Mr. F

\section{Demographics}

Mr. F is a 67 year old White male with a C6-7 spinal cord injury that resulted from being hit by a car in 1956 when he was 29 years old. He was married with three young daughters at the time. He continues to live with his wife in a home that they own. After his injury, he worked for a city public works department as a store keeper and then as a supervisor until he retired in 1982 . He used a manual wheelchair until three years ago when his decreased endurance dictated that he change to an electric one.

\section{Pre-injury Education and Work history}

Because Mr. F's father died when he was 11 years old, he worked part-time during his elementary school years, then quit school to work full-time and support his mother and siblings. Mr. F did not like school very much but, eventually, was forced by law to go to school until he was 18 years old. He went to high school at night for $21 / 2$ years, but did not pursue more education and does not have a high school diploma. 
Mr. F regrets to this day that he did not have more education. He said that had he continued his education, he could have done much better for himself. Late in life, he coached kids' sports teams and he said he saw the difference a college education made later in their lives, with a better job and better pay. He said he feels now that it is very important to have a good education.

Being the oldest employable male in his family (he had a brother with a disability), Mr. F felt responsible to support the family. He felt very proud that because of his job, his mother was able to stop working and he could afford house payments.

Mr. F learned the importance of responsibility at a very young age. He also learned to take on assignments and do them well. Although he enjoyed working, he was more interested in sports than in planning a career. He was very active in a softball league and took it very seriously.

Before going into the military when he was 18 years old, Mr. F had worked at various jobs, including being a welder in the shipyards. He said he is ashamed to say that while he was in the military, just after W.W.II, he mostly played sports.

After his discharge from the military, he became a heavy construction plumber for a California city. He said he loved the job because it was outdoors and because he never worked in one place all the time. His goal was to some day be the superintendent of his department. Eventually he became a foreman and he said he looked forward to going to work each day; he loved the responsibility and enjoyed the people who worked for him. Injury and Rehabilitation

One evening, when he was 29 years old, Mr. F was struck in the back by an 
automobile, damaging his fifth and sixth cervical vertebrae. He described it as a terrible experience for someone as physically active as he was. His youngest of three daughters was three months old at the time; he said, "It was very difficult."

Mr. F spent four months at a hospital where he had a laminectomy, then was transferred to a rehabilitation center where he spent eight or nine months. Mr. F said he did not cooperate in his first months after his injury, but when he saw other people who were "a hell of a lot worse" than he was, it made him accept "what he had." When he saw a young woman who was totally paralyzed, he said, "I was so happy that I had what I had left; it made me feel pretty damn good that I could move my arms, feed myself, and do a lot of things for myself."

He said he was surprised to be so busy at the rehabilitation hospital since he thought he would spend all day in bed. He said when he realized there was some hope, he started to "take on assignments" and do the best he could.

He said he always felt that he would walk again and it was not until three months after his injury that the doctor told him that he would not be able to do his old job. He said he appreciated that the doctor had left him the hope that he may yet walk, although he never has.

Mr. F's employers at the city were very supportive and assured him that he would have a job in his department on his release from the hospital. Mr. F said it was very important to him to know he had a job waiting for him. He was frightened that he would not be able to support his family. His mother had been on welfare when he was a child and he was determined that his daughters would not experience the same thing. Also, he 
felt that for his own being it was important to work. He felt it would be better for his mind rather than sitting home being depressed. He said he started really thinking about making up his mind what he wanted to do and that he really had to find a job. So, he said, after three to five months, an occupational therapist began helping him focus on job skills.

Mr. F relayed an incident from his time in rehabilitation which helped him and which has always stayed with him. He said that in 1956, when he was injured, most handicapped people stayed at home. His doctor, however, told him "There is something out there that you can do. I know there is."

Mr. F kept most of his fears about work to himself, not wanting his family involved in his problems. Mr. F said he feels that work issues should not be brought up within the month following an injury in order to give the patient "time to get over the shock." He said that in his case, it took four or five months or longer, but with shorter hospital stays, he said he feels that work should be discussed in order to better prepare the patient for employment. He said he feels that patients should be told, like he was, that there is something they can do.

Mr. F worked closely with the occupational therapy staff on work issues. They helped him learn to use a hand splint, talked with him about options, and after he knew he was going to a job, they worked on skills specifically related to that job.

Mr. F said he cannot think of anything he did not like about occupational therapy. He said they were very helpful to him. He said there were people who did not like it and who complained, but he said that people with a new injury are "a touchy bunch of 
people." He advised therapists to "never give up on a patient." He said he could not have cared less at the beginning, but that after a while he realized the occupational therapists were trying to help. He said that it is not so much the physical pain as the realization that you are in a wheelchair, trying to adjust to a different type of life. He said the change is tough and takes a long time; it took him over a year to adjust.

\section{Post-injury Education and Work}

While he was in the hospital, Mr. F convinced his former superiors at work that what was needed in his department was a "store keeper." The day after he was released from the hospital, he started working eight hours a day in that job, despite his doctor's wishes that he only work four-hour days.

Although his first day on the job was very scary and he was on pins and needles, he described it as "a great day for me; I thought it was wonderful." He said most of his former co-workers were pleased to see him come back; the new people were very responsive and nice. Although people were more helpful to him than he wanted at first, it was not long before they were able to say "Get it yourself." Mr. F insisted that his coworkers not treat him differently because of his disability.

He worked hard, took on more and more responsibility and one day was offered the job of supervisor of his department, the same job he had aspired to years before his injury. His first thought was that it was being offered out of sympathy, but his boss assured him that they needed his knowledge in that position. Despite his self-doubt about his ability to do the job, he accepted it and worked in that position for ten years before his retirement at age 57 in 1982. Altogether, he worked for the city for 34 years. 
Mr. F said he received satisfaction at work after his injury by knowing he was willing to try and not hold back. He takes pride in accomplishing things as a disabled person. Before his injury, he said "I knew I could do it. Nothing to it." He said he had to "retrain" his brain for a different type of work and different responsibilities. He actually did not enjoy his job at first after his injury because he was indoors and had to report to the same of fice space every day. But, he said, he adjusted to it, realizing "this is going to be the way it is."

It took Mr. F a very long time to accept his inability to play sports. He got pleasure from the coaching he did for years after his injury, but of being an active player he said, "I missed it, I really missed it very bad."

He retired because he had gained a lot of weight, did not feel as sharp as he would have liked, and was having difficulty with the eight hour days. Upon retiring, he lost weight and felt better which gave him some regrets about retiring.

He became a bit bored after his retirement, so he sold shoes out of his home for a while and then worked for a friend in advertising for a year. He retired permanently in 1985 and said that he enjoys his retirement. He said, "I don't mind it so bad. I'm quite active ... I'm not nagging my wife all day long." He is able to drive himself in his van, so he has breakfast each morning with friends, then goes shopping or visiting friends.

Mr. F said he feels that his injury has made him a much better person. He said that his priorities had been in the wrong place and that he placed too much importance on his sports, not spending enough time with his family. He said this change did not happen right away, but eventually he said he feels he became a better father and husband. He 
also gained an appreciation for the value of a good education and is proud that he has put his daughters through college.

In 1991, Mr. F was in the hospital for four months, unable to breath without a ventilator. He said he was very depressed and did not want to live any longer. But his condition improved and he has now recovered to the point that he feels better than he did previously.

Mr. F said he looks forward to getting up in the morning and that he feels so good, in fact, that he is considering going back to work, probably as a volunteer. Mr. F's plans for the future are to live as long as he can, providing he has a good quality of life.

\section{Results and Discussion}

The data from the five case studies were analyzed for common themes in the meaning of work, the factors affecting employment, difficulties encountered upon return to work, the participants' perceptions of the efficacy of their rehabilitation, and the participants' advice to professionals working with this population.

\section{The Meaning of Work}

Question One: What is the meaning of work for men with quadriplegia from a spinal cord injury?

According to Stephens and Pratt (1989), work skills and habits develop early and are a "major force in shaping self-concept" (p. 326). All of the men interviewed grew up in blue collar families with a strong work ethic. All of the participants started working 
early in life so that by the time they were injured they had all held jobs and had defined themselves as workers.

Geist and Calzaretta (1982) contended that "work is the central function in the lives of most adults" (p. 46). This is true for the men in this study, although the focus has changed for some of the participants. For example, Mr. E said that although he worked hard before his injury, it was more something he had to do that he dreaded each day. He said that now work is something to which he looks forward, and that his whole life is geared to his job.

In analyzing the data, the meaning of work was expressed by the participants on two levels, an extrinsic level and an intrinsic one. The researcher defined extrinsic meaning as that meaning that is derived from the participants' interaction with his/her environment and which is dependent on receiving something from that environment. The extrinsic meaning of work for the participants involved meeting needs, including material needs, need for activity, and need for respect by others.

Intrinsic meaning, on the other hand, is not dependent on any expressed return from a situation. It is a meaning which is inherent for the individual in the work itself, beyond a particular set of circumstances and beyond any open recognition. Intrinsic meaning was elicited in subjective, heart-felt descriptions of the significance of work to the individuals. Both the extrinsic and intrinsic meaning of work will be discussed as they relate to the motivation of the participants to return to work. 


\section{Extrinsic Meaning}

Material needs

Before their injuries, money was a major goal of work for all of the participants. For three participants, it was to support families, for one it was to be able to afford possessions, and for another it was to save money to retire early as a rich man. Since their injuries, making money has been important to pay bills and to be independent, but more importance was attached to material gain before their injuries. One participant has realized that he does not need as much money as he thought he did before his injury when he was driven to retire early as a rich man. Priorities seem to have changed, partly because of being disabled and partly from maturity.

When asked if they would still work even if they did not need the money, all of the participants said that they would. One man said, "Yes, I'd have to because I like to." Three men said they would volunteer, one said he would start his own company, and the other said that if he made enough, his work would be managing his money.

Three participants were married with children to support when they were injured. Two of these men said their main motivation to work immediately after their injuries was to be financially independent and not have to collect social security or go on welfare. The third man worked to supplement his disability benefits. He said he would prefer not to be on social security, but he fears losing his house if he had to rely strictly on income from work.

Activity

The themes that appeared in the data regarding the need for activity included the 
value of structure of a daily schedule and opportunities for socialization. Four of the participants mentioned the importance of work in structuring their time. They said that it gave them a reason to get up in the morning and kept them from staying home and being depressed. One of them said,

I could get in the habit of staying in and laying down, and that's bad. I work so hard and stay out so late that when I come home I go to sleep and I can sleep all night. ... So, I make myself tired every day.

Interactions with peers at work appeared to be very important to all of the participants, and one participant specifically mentioned human interaction as a source of motivation to work.

\section{Respect of others}

Respect of others has been especially important to the participants since their injuries. All of the participants said that they feel respected by their peers for the quality of their work. In addition, two participants said that they feel that they are also admired for the fact that they are doing quality work despite their disability. One man said, "I think they see the fact that for me to get up and go to work and do that stuff is a little bit harder [for me] than [for] them."

Two participants added that the impact of societal expectations to work was a motivation. One of the two stated that he loved returning to work because he felt like a productive member of society again.

\section{Intrinsic Meaning}

Work has meaning to the participants beyond paying bills, keeping busy, and being 
acknowledged by others. There was a personal and heart-felt aspect to the meaning of work which was expressed in the participants' conversations with the interviewer. This subjective side to motivation seemed to add to the sense of satisfaction that the participants derived from their work. The intrinsic meaning of work was described as a driving force, as art, as being fulfilling, as a source of freedom, and as being "important for [one's] own being".

A strong sense of pride in their work was apparent in all of the participants' responses as they spoke of liking the responsibility and getting satisfaction from meeting challenges. One participant said he finds that his work is never boring because there is always something "to deal with."

Two participants mentioned the importance of a sense of control that a job can provide. One man said that with so much control of his environment having been taken away since his injury, work is one place where he can still take charge. The other participant said he enjoys what he termed professional freedom, which he described as the flexibility to do things his own way at his job.

Three of the participants said that a source of satisfaction is the idea that through their work, they are giving something back. Two participants expressed frustration at having to take so much from others due to their disabilities, but said that from their work they are able to get a sense of contributing. Two participants also said that they enjoyed teaching what they know about work to others. 


\section{Factors Affecting Return to Work}

Question Two: Which factors are most associated with a successful return to work after a spinal cord injury?

Knowledge of traits and factors found through research to be associated with successful return to work can be useful in forming a prospective picture of a patient during treatment planning. To answer Question Two, factors influencing employment are discussed. The following categories were identified in the literature as having significance in predicting employment after a spinal cord injury. They are: being a younger age presently and at the time of injury; being white and being male; having a high level of education, a high level of motivation, and sufficient functional ability; being employed prior to the injury; having good problem-solving abilities and an internal locus of control; being a repressor of feelings; having positive self-perceptions; and having social support (DeVivo \& Richards, 1992; Krause, 1992; Sullivan, 1990).

\section{Younger Age at Time of Injury and Presently}

As shown in Table 1, the age of the participants at the time that they were injured ranges from 18 years old to 40 years old. Reports on the significance of age at the time of injury in predicting return to work are mixed (McShane \& Karp, 1993), but since the participants were aged from 18 years old to 40 years old and have all worked, there is no correlation between age of injury and later employment in the current study. There is, however a correlation between the amount of education received after an injury and the age of the participant at the time of the injury. The two participants who were injured at age 40 years and 29 years, have not attended school since their injury. One man did not 
attend school after his injury partly because he had a job waiting for him upon his discharge from the hospital. The other man is the most recently injured (three years ago) and did not express an interest in attending school at this time. He also returned to his former job of being self-employed.

Two participants discussed the difficulty of working at an older age with a disability. They mentioned fatigue, the aches and pains associated with wheeling a manual chair, and medical complications. These findings are supported in the literature which agrees that medical factors and decreased coping ability contribute to the difficulty of working at an older age (Lammertse \& Yarkony, 1991; Stensman, 1994).

\section{Being Male and Being White}

The factors of being male and being white as predictors of employment would seem to correlate with the employment rate of the general population rather than specifically to a disabled population. Because all of the participants in this study are male, it is not possible to predict the effect of gender on employment, and although Mr. D said that he has had to work especially hard to prove himself because he is black, that was true before his injury.

\section{Higher Level of Education}

As shown in Table 1, all but one of the participants in this study are high school graduates, three out of five have attended college, and two of the five have received college degrees. The greatest predictor of post-injury employment is one's level of education. Having a high school diploma gives individuals a decided advantage, and for those with a four-year college degree, the employment rate jumps dramatically (Krause, 1992). 
All of the participants said that they learned the value of an education at a young age, but none of them were highly motivated to study before their injuries. A high school education is considered to be a high level of education in the literature, but none of the study participants, even the two men who have not attended college, seems to have been satisfied since their injuries with just having a high school diploma. As one participant said,

Had I continued my education, I could have done much better for myself. I see the difference between the kids that went on to college and graduated and the kids that didn't go to college. Better job, better pay. . . . To this day, I regret that part of it.

\section{High Level of Motivation}

Factors affecting motivation to work have been discussed in depth in answering the first research question. All of the men interviewed appear to have been highly motivated to work since they were young. It is the factors influencing motivation which varied among the participants and which changed over time. Three of the participants said that they worked primarily for the money, either to support a family or to be able to afford material possessions. At the time of the interview, all of the participants said that although the money was important, the satisfaction derived from the work itself had become a major motivation. Two of the participants attribute the difference in motivation to natural maturing rather than to the effects of their disability.

\section{Sufficient Functional Ability}

Researchers disagree on the relationship between the level of lesion and employment status, but evidence seems to point to a lower employment rate for persons with 
quadriplegia than for those with paraplegia (Castle, 1994; McShane \& Karp, 1993).

Sufficient functional ability was stated as being a predictor of employment by DeVivo and Richards (1992). In the current study, the level of lesion and functional ability were not significant factors in determining employment status. Participants in this study have varying degrees of upper extremity function. They have adapted so that the abilities they possess have been developed to be functional for them to do a job.

Table 2 describes the level of function of each participant. All of the men interviewed have quadriplegia. They have varying degrees of arm strength. None of the men has elbow extension and only Mr. D has any finger movement, though it is slight and only in his left hand. None of the participants walks. Mr. E recently spent some time in rehabilitation attempting to walk with braces and crutches, but he said that his walking is not functional.

The two men with the least functional ability are able to perform job requirements, but ancillary needs, such as transportation and attendant care impact their employment. For one participant, it is the fact that his attendant must accompany him to the job site. For much of the day the attendant has nothing meaningful to fill his/her time and this concern impedes the participant's ability to take on a job in which he would have to work full time at an office. Another participant has little functional movement, but he is able to perform the job of consultant and supervisor. However, because he cannot drive, he is dependent on friends or public transportation to get to the job site. Despite these obstacles, it would appear that the term "sufficient functional ability" is relative to the 
Table 2

Level of Upper Extremity Function

\begin{tabular}{llclll}
\hline & Mr. A & Mr. B & \multicolumn{1}{c}{ Mr. D } & Mr. E & Mr. F \\
\hline Arm & $\begin{array}{l}\text { strong } \\
\text { biceps, } \\
\text { no triceps }\end{array}$ & some biceps & $\begin{array}{l}\text { biceps, } \\
\text { some triceps } \\
\text { on left }\end{array}$ & $\begin{array}{l}\text { strong biceps, } \\
\text { no triceps }\end{array}$ & $\begin{array}{l}\text { strong biceps, } \\
\text { no triceps }\end{array}$ \\
Wrist & extension & none & $\begin{array}{l}\text { movement on } \\
\text { left }\end{array}$ & $\begin{array}{l}\text { more flexion } \\
\text { than } \\
\text { extension }\end{array}$ & $\begin{array}{l}\text { strong } \\
\text { extension }\end{array}$ \\
Hand & none & none & $\begin{array}{l}\text { slight finger } \\
\text { movement } \\
\text { (left) }\end{array}$ & none & none \\
\hline
\end{tabular}


motivation of the individual to function at the level of ability that he/she possesses.

Being Employed Prior to the Injury

All of the participants were employed prior to their injuries. Three of the five men had worked since their early teens. One participant grew up on a ranch and although he was not employed before graduating from high school, he had to get up early every morning to complete his daily chores.

Most people with quadriplegia have a different job after being injured (DeVivo \& Richards, 1992). Table 1 illustrates the fact that all of the men changed the nature of their work, although two of them continued to work in the same company. They are also the two men who were the oldest at the time of their injuries.

\section{Good problem-solving abilities}

The participants in this study have all had jobs of responsibility in which problemsolving was a necessary aspect of their work. They have demonstrated problem-solving skills not only in their work environment, but also in their adjustment to their disabilities. One participant identified problem-solving as a motivation not only at work, but in his life. He explained,

It's very rewarding to go to work, find a problem and be able to fix it and have it work. I guess in a lot of ways, that's how I approach my life. I see a problem and

fix it. I don't sit there and bitch about it, I fix it ... I take an active stance in my life.

Four participants mentioned the satisfaction derived from a challenging task. They seem not only to accept the responsibility, but to welcome the challenge. This 
willingness to tackle problems was evident in some of the descriptions of the difficulties they faced in dealing with a traumatic injury and the resulting disability.

It is perhaps because he is only three years post-injury that Mr. D said that just working is a challenge to him since his injury, because of the physical limitations which are imposed.

\section{Internal Locus of Control}

There are mixed findings in the literature on the role of one's locus of control on eventual return to work (Fuhrer et al., 1992; McShane \& Karp, 1993), but perceived control has been found to be associated with life satisfaction and successful adjustment to spinal cord injury (Fuhrer et al., 1992). Although the participants of the present study were not evaluated specifically to determine their locus of control, they seemed, to a greater or lesser degree, to exhibit an internal locus of control. The participants' willingness to take a pro-active role in determining the course of their lives was evidenced by comments such as, "I make things happen," and, "It was up to me [to adjust to the injury]," and "You have to try to go beyond what people say you can do."

Before his injury, Mr. D was a man in control of his own company. After his injury, he appeared to doubt his source of control, which could be in part due to the early adjustment to his injury, since he is only three years post-injury.

\section{Repressor of Feelings}

The findings of this study are that repressing feelings did not appear to adversely affect the participants' employment. None of the men interviewed shared his feelings or worries about work with anyone while in the hospital. They all said that they needed to 
be strong for their families. Two of the participants said they felt that their situation was not their families' problem, although the families in both cases were very supportive. One participant explained why he kept his feelings from his parents:

I understood when I broke my neck that I victimized the two other people [his parents], and I realized that these people had been injured and that they couldn't hold it, they couldn't touch it, they couldn't see it as I do. It wasn't their responsibility to get through it, but it was mine and it was up to me not to be negative ... I lessened their pain because they [couldn't] do anything about the hopes and the losses for their child.

There is some support for this finding in the literature. In a study of spinal cord-injured males, individuals who were repressors had higher self-concepts, and those who also had an internal locus of control demonstrated the best adjustment to their injuries (Sullivan, 1990).

\section{Positive Self-Perceptions}

The participants in this study projected an image of confidence when they related memories of their lives before their injuries; a picture emerged of men with positive selfimage. One man stated, "I know the fundamental foundation of who [I] was, was there before I broke my neck. That's what gave me strength." Another said, "Even as a kid I was pretty independent." The general impression of the participants is of men who were sure enough of themselves that they were willing to take control and take responsibility for their futures. 


\section{$\underline{\text { Social Support }}$}

All of the participants had family members who were present during their rehabilitation. All of the participants were cared for by family members after their discharge from the hospital. The relationships, however, were not necessarily smooth. Two of the participants were divorced shortly after leaving rehabilitation. One man said that although his parents loved him and cared for him, he had to constantly fight them for his independence. The family dynamics of the participant whose injury resulted from an assault by his son dramatically illustrates the complex interactions between family members. It was not pursued in this study how family dynamics affected employment, but all of the participants have strong support from family and /or friends which enables them to work, by assisting with activities of daily living or through supporting roles such as caring for the household.

\section{Difficulties in Returning to Work}

Question Three: What are the difficulties faced by men with quadriplegia from a spinal cord injury when they return to work?

All of the men in the study experienced dramatic changes in the job tasks required after their injuries. Even though two men returned to the same companies where they had previously worked, their tasks changed from requiring primarily physical abilities to requiring primarily intellectual abilities. Most of the difficulties in returning to work centered on physical or medical needs, transportation needs, disincentives to work, and worries about doing the job itself. Other difficulties mentioned were discrimination in 
hiring, architectural barriers, attendant care, and worries about being accepted by coworkers,

Despite difficulties in returning to and continuing to work, the five subjects have persisted and have all worked full time. Over time the physical needs either diminished or the individuals became adjusted to them. The ability to work at an older age was identified as being problematic due to decreased endurance and decreased strength to maneuver a wheelchair.

\section{Physical Difficulties}

The difficulty most often mentioned about returning to work was bladder management. Bladder and bowel management have been reported among the negative aspects of spinal cord injury and catheter care has been found to be a difficulty in returning to school or work after a spinal cord injury (Klemz \& Modi, 1992; Stensman, 1994). Four of the five respondents said that bladder management was a concern when they first went back to work. Two of the participants mentioned catheter care as a problem at first. but they were able to find a friend, in one case, and a co-worker in the other, willing to assist them. One participant has an attendant with him at all times who pushes his bladder every hour.

Other difficulties centered around physical limitations, such as fatigue and having to schedule extra time to accommodate the time needed to accomplish such tasks as dressing, showering, and going to the bathroom.

One participant expressed concern about the physical difficulties that he confronts when he travels for his job. Unless his wife is able to accompany him, he is unable to 
spend the night at a hotel, so he must drive long round trip distances in one day.

Two participants spoke of the difficulties of working at an older age. One of these two men retired early because of decreased endurance and the other man worries that he will not be physically able to work past the age of fifty-five. There is support in the literature for their concerns; an interaction has been found between disability and the aging process (Lammertse \& Yarkony, 1991).

\section{Discrimination}

Two of the participants said they had experienced discrimination in the workplace because of their disabilities. One of the two men said he felt that he was turned down for jobs on the basis of his disability and that he was originally hired at his present workplace as a token disabled person. The other said he is unable to get new accounts partly because he is disabled.

The passage of the Americans with Disabilities Act will make persons with disabilities more visible to the public (Ditunno \& Formal, 1994), but will not solve problems of discrimination and architectural barriers overnight (DeVivo \& Richards, 1992). One participant was told by a social security law judge that there was no reason for him to have a portable computer since he was unemployable.

Another aspect of this topic is that these men do not want special consideration just because of their disabilities. Beyond adaptations in the workplace, which enable them to do their job, they do not want to be thought of as different or special. The men who are receiving Social Security said that they just want enough compensation so that when they work full time at a job, they can pay their bills. 


\section{$\underline{\text { Architectural Barriers }}$}

Two participants experienced problems with architectural barriers when they returned to work. One man said that he was unable to do some audit jobs because the buildings were not wheelchair accessible. Even if a person's workplace is accessible, their job may require that they go to other buildings that are not accessible (Klemz \& Modi, 1992). Another man found it very difficult to maneuver in the bathrooms of the old government building where he first worked. When a new building was erected, he said that a large bathroom was built which met his needs. Both of these men were injured long before passage of the ADA, and in both cases, the employer made accommodations to facilitate the participants' performance of their jobs.

\section{Transportation}

Transportation is a vital component to holding a job. Lack of mobility has been found to delay or interfere with the development of a satisfying career (Bozzacco, 1993). All of the participants agreed that transportation is essential for their independence. One participant suggested that securing transportation was something that should be emphasized in rehabilitation. Two of the participants worried about inconveniencing other people by relying on them for transportation to work.

Three participants were driving independently within the first couple of years after their injuries. One man is driven by an attendant and another is either driven by a friend or takes city buses to job sites, but he hopes to have a van soon which he will drive independently. 


\section{Ability to Do the Job}

Three of the five participants had doubts at first about their ability to do the job itself, but these worries were not necessarily related to their disability. One man worried that his introverted nature would not fit with his new job responsibilities, while another worried about the unfamiliar jobs he had to tackle such as figuring out a budget for his department. A third participant found himself doubting his knowledge of his trade, which was a feeling that he had not experienced before his injury.

\section{Acceptance by Co-workers}

All of the participants said they were accepted quickly by their co-workers and were treated fairly and with respect. Only one participant spoke of having worried about being accepted when he first returned to work, but he said that from the beginning everyone treated him well. Three of the participants noted that it was important to them not to have special treatment; they expressed appreciation that they were expected to perform at the level of any other worker and that co-workers counted on them to be dependable.

\section{Financial Disincentives}

One difficulty mentioned by three participants was the government's financial disincentives for them to work. Two of these participants reported that they would not bc able to cover their expenses if they lost all of their benefits because of reporting income from work. One man said it kept him from taking a part-time job in college, and two men said it currently prevents them from being able to report their full income. This results in forcing them to work for less money per hour. One man said,

I haven't returned to work in the real sense. I don't get relative pay. I don't get 
equal pay for my work. That's frustrating . . . to be trapped in a system that doesn't understand you. And to know there is going to be slow movement, if there are changes, is kind of hard.

The same man explained his opinion that the laws covering benefits for disabled people were written before people with high level spinal cord injuries were surviving, and that the high costs of attendant care and medical supplies were not accounted for in figuring total income needs. It was found in the literature that the potential loss of disability and health benefits is considered a strong disincentive to work (Lammertse \& Yarkony, 1991).

The next two sections refer to the participants' experiences in, and perceptions of their time in the rehabilitation hospital. Although some of the information is not directed expressly at vocational concerns, the issues that arise are important to consider during any aspect of treatment, including during work-related activities.

\section{Perceptions of Effectiveness}

Question Four: What are the participants' perceptions of the effectiveness of occupational therapy in addressing work issues?

Perceptions of the effectiveness of occupational therapy corresponded with the amount of functional ability which the participants had during their time in the rehabilitation hospital. Table 3 shows the relationship between the amount of functional movement in the upper extremity, with the perceived effectiveness of occupational therapy. 
Table 3

Experience in Rehabilitation

\begin{tabular}{|c|c|c|c|c|c|}
\hline & Mr. A & Mr. B & Mr. D & Mr. E & Mr. F \\
\hline Years since injury & 24 & 21 & 3 & 14 & 38 \\
\hline $\begin{array}{l}\text { Time spent in } \\
\text { rehabilitation } \\
\text { setting }\end{array}$ & $\begin{array}{l}41 / 2 \\
\text { months }\end{array}$ & 11 months & 3 months & 3 months & 11 months \\
\hline $\begin{array}{l}\text { Amount of UE* } \\
\text { function during } \\
\text { rehabilitation }\end{array}$ & $\begin{array}{l}\text { biceps and } \\
\text { wrist } \\
\text { extension }\end{array}$ & $\begin{array}{l}\text { no } \\
\text { movement }\end{array}$ & $\begin{array}{l}\text { slight } \\
\text { movement } \\
\text { in left arm }\end{array}$ & $\begin{array}{l}\text { shoulder } \\
\text { movement } \\
\text { only }\end{array}$ & $\begin{array}{l}\text { biceps and } \\
\text { wrist } \\
\text { extension }\end{array}$ \\
\hline $\begin{array}{l}\text { Perception of } \\
\text { occupational } \\
\text { therapy }\end{array}$ & positive & negative & negative & neutral & positive \\
\hline *UE = upper extre & & & & & \\
\hline
\end{tabular}


The two participants who were the most positive about their occupational therapy experience had the most functional use of their upper extremities during their hospitalization. However, neither of the men enjoyed occupational therapy during the first few weeks in rehabilitation. One said that he felt they were pushing too hard and the other said he didn't think it was doing any good. The turning point seems to have been when they became motivated to take an active role in their therapy. One man said it became like going to work. The other man said that after seeing patients with less movement than he had, he began to feel lucky for what he had and started accepting his injury.

Both of these men had been promised clerical jobs by their former employers. They both said that the occupational therapists were instrumental in teaching them necessary work skills. One man emphasized the importance, for later employment, of the independent living skills, such as dressing and driving, which he learned in occupational therapy. The other spoke of how helpful the occupational therapist had been in teaching him skills to accomplish an office job, which was very different from the physical jobs he had done before. Both men said that they could not think of anything they did not like about occupational therapy.

Two of the participants did not like their experiences in occupational therapy during their hospitalization, but in hindsight they perceived that it had value. One man said that it got him to think about doing things for himself and the other said that he understands now that some of the activities which he so disliked were starting points for learning other skills. Both of these men had minimal upper extremity function during 
rehabilitation. One man has had significant return of function since his discharge from rehabilitation and the other man has had some return.

Both men said that they only attended therapy because it was required. Neither of these men addressed the issue of work while in rehabilitation. For one man, it was because he had such limited functional ability with overriding medical problems. As he said,

There wasn't a whole lot they could do with me. I couldn't feed myself, I couldn't dress myself, I couldn't bathe myself. I couldn't do anything at that point. How do you talk to somebody [in that condition] about work?

The other man, who owned his own company, was forced to make business decisions daily while in rehabilitation, but he didn't want to deal with work in therapy. He said, "I was in too bad of shape to even think about holding a job. I couldn't see it in a wheelchair."

The participant who was the most negative about his occupational therapy had no movement during rehabilitation and currently has the least upper extremity function of the sample group. He said that the therapists did not know what to do with him when he was injured 21 years ago, because patients with high level injuries were not expected to survive. It is only within the last twenty years that many individuals with injuries above C4 survived the initial trauma (Lathem et al., 1985). He said the occupational therapists were unable to provide him with meaningful activity because he was so limited and the options were so narrow. He said they did not give him any information on employment possibilities, partly because they didn't know the options themselves. 
He said that the therapists were not realistic in their recommendations to learn to cat independently or do daily range of motion exercises. He said that for him to be active in the competitive work world, those activities take too long and require too much energy to be practical. He explained,

Who wants to sit there [with their arms in a trapeze] and take fifty minutes to eat their god damned breakfast? They're not realistic. If you're going to be competitive in the real world, you've got to do competitive things and you've got to do them on time just like everybody else. They're teaching you how to have an easy life in a convalescent home. They are not teaching you how to survive.

He concedes that therapists have probably changed since he was in rehabilitation twenty-one years ago. But Carpenter (1994) found similar complaints of a gap between what is taught in the rehabilitation environment and what is needed in the community among study participants who were injured three to five years ago. And in a study conducted in 1985, Pendleton (1990) found that independent living skills, including vocational skills, were not being adequately addressed by occupational therapists in inpatient rehabilitation settings.

There was agreement among all of the participants that very early in the hospitalization, other considerations take priority over work issues, but they said that the adjustment time needed is different for each individual. One man described his experience,

More than anything else, [it] was [like] everything I understood to be true wasn't true anymore. My reality had changed and it was like being bopped over the head 
and being dazed and trying to gather your thoughts and go on. Slowly but surely things started coming together.

There were mixed statements about the length of stay in rehabilitation. One man who spent three months in rehabilitation said that they sent him home too soon, before he was able to sit up more that a few hours at a time. The two men who were in the hospital the longest, eleven months each, wished that they could have gone home sooner. Another participant, who went home after three months in rehabilitation (two months earlier than planned) said that he was glad to leave the hospital and that he felt that going home was "another milestone in [his] recovery."

The fifth participant said he felt lucky to have had five months of rehabilitation since hospital stays are shorter now. He said he doesn't know how people could develop necessary skills in a shorter time. He said he was immobilized in traction and then a brace for the first few months of rehabilitation and that it was not until after the brace came off that he really began to work hard in therapy.

Three of the five participants spoke fondly of the personal relationships that they formed with their occupational therapists. These three men were in therapy the longest time ago and spent the most time in rehabilitation. The complaint that seemed the most common was that when there was little functional movement of the upper extremities, which is true for many patients with quadriplegia early in their rehabilitation, the value of occupational therapy was not apparent. 


\section{Participants' Recommendations}

Question Five: What recommendations do the participants have for occupational therapists working with persons with spinal cord injuries in a hospital setting for patients with acute or subacute conditions?

The researcher asked the question, "When should an occupational therapist bring up the issue of work?" The results varied, echoing the lack of agreement in the literature as to when vocational concerns should begin to be addressed (Alfred et al., 1987; Kanellos, 1985; Sullivan, 1990). Two of the participants said that it depended on individual needs, explaining that some patients want to crawl in a shell and not deal with their situation. One participant said that for him, it should have been brought up immediately to let him know his options. Another man said that occupational therapists should prepare a person for work, but that they should allow at least a month for him/her to get past the shock of the injury. The fifth participant was forced by his family to face work issues shortly after his injury because of being self-employed, and he said it was a nightmare.

The participants were asked what advice they would give an occupational therapist working with a man with a spinal cord injury. Two themes that emerged from the responses to this question will be discussed below. Although the themes do not necessarily relate directly to work, the researcher felt that they were important issues to be discussed since they apply to general treatment planning which could include addressing vocational needs.

Therapeutic Approaches

The first theme that emerged concerned the importance of an individualized 
therapeutic approach by the rehabilitation professionals. The participants described the therapeutic approach that each felt would have worked best for him, but each acknowledged that his preferred style would not necessarily work with every patient. Two of the participants wanted to know the facts so that they would be able to plan their futures realistically and move on. They said it was important not to dwell on the past. One of the two men described his feeling that people should not just be told what they want to hear,

It was tough when the doctor told me that I wouldn't walk again and what my prognosis was, but I thank him for it because he gave me reality and it helped me set my sights as to what I needed to do.

Two other participants had different expectations of the rehabilitation professionals; they said that it was important to them to retain the hope that someday they might walk and be able to do more things for themselves. The following quote is the reaction of one of these participants to his doctor's approach. It contrasts sharply with the passage above.

I always felt I would walk again. After about the third month, I asked [the doctor] what's the chance. He said, 'I don't think you will ever install any more water pipes.' He did not say I would spend the rest of my life in a wheelchair. That would have been devastating to me.... I thought that was great the way he presented it to me.

Three of the participants said that people should not be pushed in therapy, rather they should be guided, funneled, or helped to focus. Two of the three, however, said that 
there is a time when the patient must work through their disability and "get over it," although there is no formula for when that should be since everyone's needs are different.

Two participants said that occupational therapists need to be patient with persons with spinal cord injuries at first because they are in such mental pain. They said not to give up, even though some patients may be hostile or unmotivated. One man said he could not have cared less about therapy at the beginning. He described newly injured patients as "a touchy bunch of people."

Two participants said that it is important to have expectations of independence for patients and that they must be challenged. One of these participants discussed what he considered to be the danger of encouraging a patient to be dependent. He said,

I know it's easy to fall into a trap and I saw other people fall into it where the family, they just want to help and they see you struggling with something and they want to make it easier for you . . . that doesn't help anyone because then it doesn't allow them to determine what they need and what they can do for themselves. The importance of active participation by patients in their treatment was noted by Kanellos (1985) as being valuable in addressing vocational issues.

\section{Availability of Information}

The second theme was the importance of the availability of information, which encompassed the clarity of therapy goals, knowing the employment options, and having a role model for successful employment. 


\section{Clarity of goals}

Two participants mentioned that some aspects of their occupational therapy were not clear to them and that it was only through hindsight that they understood the purpose which the therapist had in mind. One man said that he didn't understand at the time why some personal questions were asked. He stressed that it was not a major concern at the time and that he realizes now that the therapists wanted to have a clearer idea of his emotional state and his expectations. The other participant considered the therapists' lack of clarity in explaining the purpose of activities to be a critical factor in his lack of acceptance of occupational therapy. He explained,

The sanding board, they didn't make [the reason for it] clear. My pride said, 'Hell, I have people [at work] doing that for me.' The reason for me sanding was not for me to have a board, it was for exercising my arm. ... if I had known, I would have worn the wood out.

It must be noted here that this participant also said that he skipped many physical therapy treatments. Since physical therapy uses exercise as a modality, it is unclear whether an explanation of the sanding activity as an exercise would have added any motivation. However, the problem of a lack of information was also identified in a study of newly injured patients. It was found that they did not receive enough information to have a clear idea of rehabilitation goals (Krishnan et al., 1988) and that it adversely affected their perception of the effectiveness of rehabilitation.

\section{Knowing the options}

Two participants emphasized the importance of letting patients know about 
vocational possibilities and that there is something that they can do, no matter how severe the disability is. Passage of the ADA ensures that even the most severely disabled person must be considered for employment (Rybski, 1992), so therapists must be aware of the options, or at least a community referral source that could provide information on vocational options.

\section{Role model}

All of the participants said that it would have been helpful to speak with a person with a spinal cord injury who was living successfully in the community. One participant said that it was encouraging to see patients who came to the rehabilitation hospital for follow-up visits because he, he said, "You got to see people that were out in the real world ... [it was] helpful to see people out there like that." The other participants gave various reasons why a role model would be valuable. One man said that an injured person would be more credible since he/she is in a wheelchair. He/she would be able to give information on what to expect, how to solve everyday problems, and be a role model to show that things do get better. One participant added that a Black person might be more comfortable listening to another Black person. Contact with persons with similar injuries who have completed rehabilitation and can provide a long-term perspective was suggested in the literature so that patients know the possibilities for a satisfying future (Patterson et al., 1993). An occupational therapist could promote the idea of having people with spinal cord injuries visit a facility as a transdisciplinary effort which could lend itself well to a group format. 


\section{CHAPTER 5 \\ PROFESSIONAL IMPLICATIONS, RECOMMENDATIONS, AND \\ SUMMARY}

Introduction

The current role of the occupational therapist in addressing work issues with persons with spinal cord injuries in an acute or subacute rehabilitation setting is influenced by several factors, including: shorter length of time of inpatient rehabilitation; overwhelming medical and emotional needs of the patients, especially those with highlevel injuries; and the demands of third-party payers for measurable treatment outcomes.

Despite these limitations, however, an occupational therapist practicing in a rehabilitation hospital can have a significant role in advancing a patient toward returning to meaningful work. (Hammell, 1992; Kanellos, 1985). Implications of the findings are discussed as they relate to suggestions in the literature on the possibilities for development of an effective role. Possible avenues of change are explored, the implications are related to occupational therapy theory, and suggestions for further research in this area are proposed. 
Professional Implications

The meaning of work in the lives of the participants cannot be overstated. It provides financial security for all of the participants and financial independence for three of them. Work provides challenge and gives structure to their days, and it gives at least three of them a reason to get up each day. Employment is a major source of pride and self-respect. And it is an activity that is enjoyed for its intrinsic value; all of the participants like to work and they enjoy the jobs they do.

Two main themes emerged from the review of the literature and from the interview data which impact on how vocational issues could be included in the occupational therapy treatment plan. First, there are many factors affecting how directly vocational issues can be addressed during inpatient rehabilitation, including: the length of hospital stay, the requirement of documentable outcomes, the degree of upper extremity function, the knowledge of the occupational therapist concerning work issues, the effectiveness of communication between an occupational therapist and a patient, and the patient's motivation to work. The second theme is that the meaning of work to a patient can be an important source of information about how occupational therapists can meet a patient's vocational needs.

\section{Factors in Addressing Vocational Issues}

Studies have indicated that active vocational planning and training may not be possible during inpatient rehabilitation for a person with a spinal cord injury. Alfred et al. (1987) asserted that active vocational planning is not realistic during inpatient 
rehabilitation or during the first few months after discharge. The findings of the current study research suggest that there are many factors affecting how vocational issues can be addressed during rehabilitation. The participants related experiences in rehabilitation which spanned from 1956 to 1991 . This covers a long history of occupational therapy and reflects differences in practice that may have affected how vocational issues were and are addressed. The two men who were in rehabilitation the longest ago received the most direct vocational training and had the longest stays in rehabilitation. It must be noted here that these two men also had the most return of upper extremity function and had been promised jobs upon discharge from the hospital. This study found that although the participants had significant similarities in their levels of motivation to work, their expectations of and needs from occupational therapy were quite different The findings of the present study point to several factors that may affect how directly an occupational therapist can address vocational issues during inpatient rehabilitation.

\section{Length of Hospital Stay}

As hospital stays become shorter (Ditunna \& Formal, 1994), the majority of occupational therapy treatment will be limited to the acute phase of a patient's recovery when they may not be ready to think about work due to being overwhelmed by the magnitude of their situation (Alfred et al., 1987). When a spinal cord injured patient is first seen in rehabilitation, he/she is often immobilized in a brace or a halo, is in psychological and physical pain, and concentrating on basic survival rather than issues such as work. In a hospitalization stay of three months (the average stay in rehabilitation in 1988), patients may not arrive at a point where they are ready to actively pursue 
vocational skills or consider vocational planning before their discharge. The two participants who were the most active in vocational training had long hospitalizations of five and eleven months respectively. In a shorter stay, there may be minimal upper extremity functional return, limiting the use of physical activities relating to work. Also, the choice of a clinical reasoning method may be dictated by the limited time which a therapist spends with a patient; narrative reasoning is a valuable method for formulating a holistic picture of a patient, but it may not be practical as it is described by Mattingly (1991), given inpatient time constraints.

There are important goals to be achieved in the first few months of rehabilitation that are not predicated on length of stay or amount of upper extremity function. In keeping with the premise of Helfrich et al. (1994) that a person's life in therapy is ongoing and that treatment must be based on that concept, inpatient rehabilitation of persons with spinal cord injuries may be considered as laying the groundwork for future vocational development. There are references in the literature that indicate that vocational development may begin in the rehabilitation hospital, but it is an ongoing process for years after discharge (Hammell, 1992). The work lives of all of the participants continued to evolve long after their discharge from the hospital. Researchers stress that vocational goals are not only promoted by vocational assessment and training; the importance of providing opportunities for a sense of control and responsibility, for independent problem solving and decision-making, for access to information, and for learning of self-care skills, must be incorporated into practice. 


\section{Documentation Requirements}

The second factor affecting how vocational issues are addressed is that the medical system is driven by reimbursement issues and therapy goals are dictated by the demands by third-party payers for functionally-based documentation. Hammell (1992) contended that rehabilitation "does not consist purely of learning adeptness at physical skills" (p. 325). Three of the participants had very little upper extremity function during their time in rehabilitation and these three men said that they did not benefit significantly from their occupational therapy and that work issues were not addressed. It seems that the participants themselves may have measured success according to physical skills. Not only must therapists identify realistically attainable, documentable vocational goals that are not reliant on physical skills, but these goals must be made clear to the patients and it must be explained how treatment will support the patient's potential for returning to work, even if training in specific work skills are not part of the treatment plan.

\section{Degree of Upper Extremity Function}

The survival rate of people with high level cervical injuries has increased dramatically in the past fifteen years. These people now have greater vocational options and expectations. The participants with the least functional ability during their rehabilitation were the most negative about their time in occupational therapy. Although there was research in the mid-1980's regarding occupational therapy for persons with high-level injuries, there has been scant attention paid to the subject in the occupational therapy literature in recent years. The medical system has continued to change 
dramatically since the mid-1980's and persons with high-level injuries are greatly affected by the changes, as discussed in the two previous sections. With so few recent studies in the occupational therapy literature on strategies for addressing work issues with people with little or no upper extremity function, research may fall to clinicians working with this population.

Knowledge of the Occupational Therapist

Pendleton's (1990) study found that vocational issues are under-represented in planning occupational therapy in rehabilitation hospitals. The author suggested that one possibility for so little time being spent on work issues may be that the therapists' knowledge may be lacking in this area. Lack of information as a deterrent to vocational development was identified in the current study and is corroborated in other research. In order for a therapist to effectively inform a patient, the therapist must acquire certain basic knowledge.

First is the need for the therapist to be aware of vocational options, including the latest technology. This could be particularly important in working with persons with high cervical injuries, who are reliant on technological advances. New technology can have a major impact on a spinal cord injured person's ability to perform a job. It is crucial that an occupational therapist working with this population either be informed of the technological options or have that information available to the patient. The participant with the highest level injury, who was injured 21 years ago, said that one of the greatest detriments to his working was not having many vocational options at that time and not knowing what the existing options were. He said that his occupational 
therapist didn't know the options either. But now there is a wealth of opportunities in computers and it is imperative that occupational therapists be versed on the possibilities in order to give patients hope and a goal toward which to work. Therapists must remain current on the "explosive expansion of electronic technology" (Garber, 1985, p. 704) which could be instrumental in vocational training.

The second area of knowledge for the occupational therapist to be aware of is a patient's psychosocial needs. There is evidence in the literature, supported by the current study, that patients' moods and frames of mind are often misinterpreted by professionals, especialiy experienced professionals. Patients tend to be less depressed and more optimistic that the professionals expect. Patterson et al. (1993) contended that, "Because there are frequent misconceptions about [long-term psychosocial function] after a spinal cord injury, those providing the information must be familiar with the literature"(p. 507). This could affect how the therapist approaches treatment planning and the level of expectations he/she might have of the patient. One participant with a high-level injury had this advice for occupational therapists, "Have expectations." A therapist who assumes that a patient is more depressed than he/she is actually experiencing might have lower expectations for success, doing the patient a great disservice.

Third, a therapist should be aware of, and able to communicate, information which would be applicable in the patient's home and community, such as attendant care communication and using public transportation systems. In order to become informed, a therapist should be aware of the obstacles to employment, such as financial disincentives, that are encountered by persons with spinal cord injury, and also the factors, such as 
education, which appear to support eventual employment. A valuable source of this information could be former patients living in the community and this option will be discussed in the following section.

\section{Effectiveness of Communication}

One factor that may affect the communication of information between a patient and a therapist is how receptive a newly injured patient is to the information provided during rehabilitation, when the patients are coping with overwhelming medical and emotional needs. For example, there is a service available at a Bay Area hospital in which people with spinal cord injuries, who are living in the community, come to the hospital to talk with newly-injured patients. Many of the patients reject the offer because they are not ready to admit that they may be disabled for the rest of their lives. Some of these patients later regret the lack of information; with patients being discharged earlier after their injuries, this could become a more common problem.

The participants of this study all agreed that a former patient could act as a role model and a source of information, but only one of the participants had this kind of contact during his rehabilitation. Since the information and inspiration of a former patient is considered to be valuable, perhaps the stories of successful working people with quadriplegia could be available in a written form so that they could be perused at the discretion of the patient Since a sense of control is also an issue for persons with spinal cord injury, it is important that they have the opportunity for control over when they are ready for information. Since this may not happen until after discharge from rehabilitation, the written material could be taken home for future referral. 


\section{Patient Motivation to Work}

Although no studies were found in the occupational therapy literature on this specific topic, the findings of this study indicate that the degree to which an individual is motivated to work in therapy cannot predict vocational outcome. If a patient is not motivated to perform in therapy it may have no correlation with his/her motivation to eventually be employed. One participant reported that he thought that occupational therapy was not relevant to his life and another participant said that he skipped many therapies, yet both men work full days and continue to be highly motivated to work.

Pilsecker (1990) said that "six months after discharge may be too soon to get an accurate reading of whether or not, at some point in time," a person with a spinal cord injury will expend the necessary effort to maintain regular employment (p. 93), yet the men in the current study possessed many of the attributes identified in the literature as being associated with successful employment after a spinal cord injury. A therapist can form an effective treatment plan for an individual by being aware of information about vocational development for persons with spinal cord injury, being informed of the person's past work history, understanding what work means to that person, and recognizing how that meaning affects the person's motivation to work.

\section{Significance of the Meaning of Work}

The literature offers important suggestions for addressing vocational issues even in early hospitalization. Through the expressed meaning of work for the participants, the findings of the present study provide clues as to how the suggestions can fulfill patients' needs. 


\section{Source of Independence}

Work is a source of independence for the men in the study. It is important, therefore, that opportunities for independent decision-making be provided. Independence in self-care and particularly bladder management will build confidence, provide a sense of control, and directly affect the ability to function in a job.

Kanellos (1985) contended that the patient must be provided with "as many opportunities for direct control over the hospital environment and rehabilitation outcomes as possible" (p.729). Patients must be included in the planning process to avoid what Trieshmann (1980) referred to as learned helplessness. Two participants echoed this idea of the danger of encouraging a patient to be dependent. Two other participants seemed to have gained a sense of control only through their rebellion against the rehabilitation facility routines. The theory and philosophy of occupational therapy support the encouragement of a patient's independence. Occupational therapists working in the current hospital environment, which permits little independence or decision-making by the patients (Trieschmann, 1992), must find ways within the current health care climate to fight the time pressures that may make dictation of goals to patients attractive.

\section{Challenge and Success at Problem-solving}

The participants enjoy the challenges and success at problem-solving that work provides. One of the major frustrations for the participants who had little upper extremity function during rehabilitation was their inability to succeed at the activities in occupational therapy. Another problem for at least two of the participants was that the activities in which they could participate had little meaning to them, so they were not 
gratified by the success they did achieve. Challenge and success must be balanced so that the challenge is not so great that success is not attainable or so little that success is meaningless.

\section{Structuring Time}

The importance of structuring one's time cannot be over-looked or trivialized. It must be understood that this is not just keeping busy, it is having something meaningful to look forward to and that serves as a motivation to act. For at least three of the participants, work is the reason to get up in the morning.

\section{Implications Related to the Model of Human Occupation}

To summarize the findings of the present study as they relate to the Model of Human Occupation, it is necessary to briefly review the model. The human being is viewed as an open system with three subsystems, volition, habituation, and performance. This study focused on the volition subsystem which is comprised of personal causation, valued goals, and interests. A recent addition to the volition subsystem is the concept of discovering the meaning of an individual's experience from the personal narration, or story, of that individual. Each of the three parts of the volition subsystem, as well as the addition of meaning into the model, will be discussed as related to the findings of this study. 


\section{Personal Causation}

Of the three parts of the volition subsystem, personal causation, or the degree to which an individual perceives to be in control of events affecting his/her life, appears to have had the most relevance to, and impact on, the eventual employment of the participants. The participants had a strong sense of inner control; they all seemed to feel that they were responsible for their future work lives and took action which led to their eventual employment.

Two of the participants seemed to gain control through achievement of skills and two others used rebellion against the rehabilitation facility rules to gain a sense of independence. It is imperative in this case that the occupational therapist not take control away by forcing compliance. This is a challenge for the occupational therapist who is often dealing with, as one participant described, "a touchy bunch of people." The fifth participant left rehabilitation before he was able to achieve any independence, however it was not long before he took charge of teaching himself independent living skills at home.

The participants had been highly motivated to work from a young age, they had a high level of independence, and they were determined to live a full life. It is possible that the participants would have worked regardless of the occupational therapy that they experienced in rehabilitation, partly because of their determination to succeed by taking action to retain control of their futures.

There is general agreement in the literature that therapists need to provide patients with opportunities to achieve a sense of control over their environment. The research suggests that vocational planning can be advanced if control can be experienced by a 
patient in a rehabilitation setting.

\section{Valued Goals and Interests}

The participants had to change the work goals that they had set before their injuries. None of the men could continue to do the same job as before. During a short rehabilitation, it is unlikely that a spinal cord-injured person with quadriplegia would be ready or able to determine realistic goals. As with valued goals, specific interests related to work could be of value for deciding on therapeutic activities, but may have limited relevance to future employment for a newly-injured patient.

\section{Meaning}

One thing that became clear to the researcher in the process of conducting this study is that human beings are complex and cannot be understood by traits alone. Knowing the participants' work interests or goals, even if the participants knew what they were at the time of their injuries, would say little about their potential for employment or their motivation to work. Without the added dimension of meaning in the volition subsystem, an incomplete picture or story of an individual is derived.

Gathering a comprehensive history of the injured person from that person, as well as from the family, is part of most occupational therapy evaluations. In gathering historical information from the patient, the patient's past traits and motivation to work should be noted and incorporated into treatment planning, but should not be presumed to present a complete picture of the total person. Nor should it be used to predict a person's potential 
for returning to work. Unfortunately, it may be a time-consuming proposition to gather comprehensive information through personal narration and it may require an experienced therapist to draw out the information and to apply the knowledge to treatment, but the results of this study show how beneficial that information could be in understanding a patient's needs. Goals and interests may be the more tangible expressions of the underlying meaning of experience. Though goals and interests may have to change in the adjustment to a spinal cord injury, meaning may be a thread that a therapist could rely on to give a more stable picture of an individual.

\section{Recommendations}

The present study was limited to five men with quadriplegia who have histories of long-term employment. Although the data collected are rich, greater understanding of the implications of the study would result from comparisons with data from other studies using the interview guideline developed by the researcher. Potential populations could include persons with spinal cord injuries with quadriplegia who: 1) are female, or 2) who have never worked since their injuries, or 3) who had college degrees before their injuries.

Several procedural changes would have improved the current study. A pilot study would have provided valuable information on the interview guideline questions and the interview process. The depth and richness of the data could have been enhanced by a follow-up interview, rather than the telephone follow-up questions. One recommendation is to conduct the follow-up interview at the participant's place of work, 
if possible, in order to have a more complete picture of a working person.

More research is needed about how occupational therapists are currently addressing vocational issues in the rehabilitation hospital setting. Since Pendleton's (1990) survey of occupational therapists was conducted in 1985, changes in length of hospital stay and increasing demands for documentation of functional outcomes may have further diminished the .55 percent of rehabilitation time found to be spent on work issues. A follow-up study is warranted, including an explanation of the treatment strategies that are incorporated into the time spent on work issues. An important piece missing from current occupational therapy research is the perception of occupational therapists themselves on rehabilitation for this population.

The impact of social support on one's future employment was not fully explored in this study, but could be a valuable area for further research. Another area for further study is the assessment of coping styles and their impact on employment.

\section{Summary}

This was a study of the working lives of five men with quadriplegia resulting from a spinal cord injury. The participants were interviewed about their education and work history, their experience in rehabilitation, and their working lives since their injury.

Common themes in the meaning of work, factors affecting employment, difficulties in returning to work, perceptions of the effectiveness of occupational therapy in meeting their work-related goals, and the participant's advice to occupational therapists working in rehabilitation were identified. The most common motivations to work were: economic 
security and independence, commanding the respect of others, and intrinsic feelings of pride in one's work and enjoyment of the challenges confronted on the job. Although four out of five participants agreed that work has different meaning to them since their injury, two of the five men said this may be due to natural aging and maturing rather than to their disability.

The most common predictors of post-injury employment in the present sample were a high school education, internal locus of control, being a repressor of feelings, and having problem-solving skills. Difficulties returning to work included physical concerns, particularly bladder management, discrimination, architectural barriers, transportation, worries about being able to do the job, and financial disincentives.

As for their time in rehabilitation, the experience of being overwhelmed initially by medical and/or emotional concerns was universal for the participants. Two of the five participants were positive in their perceptions of the effectiveness of occupational therapy in addressing work issues. These men had long hospital stays, high functional ability, and the promise of a job upon discharge. The other three men had little functional ability while in rehabilitation and did not perceive occupational therapy as effective in the area of vocation.

The participants agreed that an appropriate therapeutic approach differs among individuals. Their concern about the availability of information centered on the lack of clarity of treatment goals and not being aware of vocational options. They all agreed that a spinal cord-injured person working in the community would be a helpful role model to a newly injured patient. 
Implications for practice focused on the need to identify a role for occupational therapists in addressing work issues in the rehabilitation hospital, especially for patients with little upper extremity function. Among the factors affecting this role are shorter hospital stays, demands for functional goals, and the explosion of computer technology. The meaning of work was described by the participants as a source of independence and control, challenge, success at problem-solving, and structuring time in a meaningful way. The meaning of work for the participants may provide clues as to how suggestions in the literature for addressing vocational issues early in rehabilitation can be adapted by the clinician to meet patients' needs.

In view of theory and the findings of this study, work issues may not be receiving appropriate attention from occupational therapists in the rehabilitation hospital. Many factors affect how directly vocational issues can be addressed, but even with constraints of a cost-controlled health care system, the foundation for future employment could be laid early in a patient's stay with the acknowledgment that vocational development will be ongoing long after discharge. This is a goal worthy of consideration and further study. 


\section{REFERENCES}

Alfred, W. G., Fuhrer, M. J., \& Rossi, C. D. (1987). Vocational development following severe spinal cord injury: A longitudinal study. Archives of Physical Medicine $\underline{\text { and Rehabilitation, }} \underline{68}, 854-857$.

Baum, C. M. (1985). Growth, renewal, and challenge: An important era for occupational therapy. American Journal of Occupational Therapy, 39, 778-784.

Bozzacco, V. (1993). Long-term psychosocial effects of spinal cord injury. Rehabilitation Nursing, 18(2), 82-87.

Branholm, I-B., Eklund, M., Fugl-Meyer, K. S., \& Fugl-Meyer, A. R. (1991). On work and life satisfaction. Journal of Rehabilitative Sciences. 4 (2), 29-31.

Burke, J. P., \& Cassidy, J. C. (1991). Disparity between reimbursement-driven practice and humanistic values of occupational therapy. American Journal of Occupational Therapy, $45,173-176$.

Carpenter, C. (1994). The experience of spinal cord injury: The individual's perspective-implications for practice. Physical Therapy, 74, 614-627.

Castle, R. (1994). An investigation into the employment and occupation of patients with a spinal cord injury. Paraplegia, $\underline{32}, 182-187$.

Christiansen, C. (1991). Occupational therapy: Intervention for life performance. In C. Christiansen \& C. Baum (Eds.), Occupational therapy: Overcoming human performance deficits (pp. 3-44). Thorofare, NJ: SLACK. 
Crewe, N. M., Athelstan, G. T., \& Bower, A. S. (1978). Employment after spinal cord injury: A handbook for counselors. Minneapolis: Department of Physical Medicine and Rehabilitation, University of Minnesota.

Crisp, R. (1992). Vocational decision making by sixty spinal cord injury patients. Paraplegia, $\underline{30}, 420-424$.

Cromwell, F. S. (1985). Work-related programming in occupational therapy: Its roots, course and prognosis. Occupational Therapy in Health Care, 2(4), 9-23.

Cushman, L. A., \& Dijkers, M. P. (1990). Depressed mood in spinal cord injured patients: Staff perceptions and patient realities. Archives of Physical Medicine and Rehabilitation, 71, 191-196.

Cushman, L. A., \& Hassett, J. (1992). Spinal cord injury: 10 and 15 years after. Paraplegia, 30, 690-696.

DeJong, G., \& Batavia, A. T. (1991). Toward a health services research capacity in spinal cord injury. Paraplegia, 29, 373-389.

DePoy, E., \& Gitlin, L. N. (1994). Introduction to research: Multiple strategies for health and human services. St. Louis: Mosby.

DeVivo, M. J., \& Richards, J. S. (1992). Community reintegration and quality of life following spinal cord injury. Paraplegia, $\underline{30}, 108-112$.

Devivo, M. J., Rutt, R. D., Stover, S. L., \& Fine, P. R. (1987). Employment after spinal cord injury. Archives of Physical Medicine and Rehabilitation, $\underline{68}, 494-498$.

Ditunno, J. F. \& Formal, C. S. (1994). Chronic spinal cord injury. The New England Journal of Medicine, $\underline{330,}$ 550-556. 
Eisenberg, M. G., \& Falconer, J. A. (1978). Treatment of the spinal cord injured. Springfield, IL: Charles C. Thomas.

Ellexson, M. T. (1989). Work hardening. In S. Hertfelder \& C. Gwin (Eds.), Work in progress: Occupational therapy in work programs (pp. 67-124). Rockville, MD: American Occupational Therapy.

Ernst, F. A. (1987). Contrasting perceptions of distress by research personnel and their spinal cord injured subjects. American Journal of Physical Medicine, $\underline{66}(1), 12-15$.

Frank, R. G. \& Elliott, T. R. (1987). Life stress and psychological adjustment following spinal cord injury. Archives of Physical Medicine and Rehabilitation, 68, 344-347.

Fuhrer, J. J., Rintala, D. H., Hart, K. A., Clearman, R., \& Young, M. E. (1992). Relationship of life satisfaction to impairment, disability, and handicap among persons with spinal cord injury living in the community. Archives of Physical Medicine and Rehabilitation, 73 , 552-557.

Garber, S. L. (1985). New perspectives for the occupational therapist in the treatment of spinal cord-injured individuals. American Journal of Occupational Therapy, $\underline{39}$, 703-704.

Geist, C. S., \& Calzaretta, W. A. (1982). Placement handbook for counseling disabled persons. Springfield, IL: Charles C. Thomas.

Glass, C. A., Krishnan, K. R., \& Bingley, J. D. (1991). Spinal injury rehabilitation: Do staff and patients agree on what they are talking about? Paraplegia, 29, 343-349.

Guralnik, D. B. (Ed.). (1970). Webster's new world dictionary of the American language. New York: World. 
Hammell, K. R. W. (1991). Occupational therapy in the management of high level quadriplegia. British Journal of Occupational Therapy, 54, 333-340.

Hammell, K. R. W. (1992). Psychological and sociological theories concerning adjustment to traumatic spinal cord injury: The implications for rehabilitation. Paraplegia, $\underline{30}$, 317-326.

Hanson, C. S., \& Walker, K. F. (1992). The history of work in physical dysfunction. American Journal of Occupational Therapy, 46, 56-62.

Harvey-Krefting, L. (1985). From another perspective: An overview of the theme. Occupational Therapy in Health Care, 2(4), 3-7.

Helfrich, C., \& Kielhofner, G. (1994). Volitional narratives and the meaning of therapy. American Journal of Occupational Therapy, 48, 319-326.

Helfrich, C., Kielhofner, G., \& Mattingly, C. (1994). Volition as narrative: Understanding motivation in chronic illness. American Journal of Occupational Therapy, $\underline{48}, 311-317$.

Howard, B. S. (1991). How high do we jump? The effect of reimbursement on occupational therapy. American Journal of Occupational Therapy, 54, 875-881.

Kanellos, M. C. (1985). Enhancing vocational outcomes of spinal cord-injured persons: The occupational therapist's role. American Journal of Occupational Therapy, 39 , 726-733.

Kielhofner, G. (1983). Health through occupation: Theory and practice in occupational therapy. Philadelphia: Davis. 
Kielhofner, G., \& Burke, J. P. (1980). A model of human occupation, part 1. Conceptual framework and content. American Journal of Occupational Therapy, $\underline{34}, 572-581$.

King, P.M. (1992). Outcome analysis of work-hardening programs. American Journal of Occupational Therapy, 47, 595-603.

Kirschbaum, H. (1991). Disability and humiliation. Journal of Primary Prevention, 12 , 169-181.

Klemz, S. \& Modi, S. S. (1992). The arduous road to recovery. Spinal Cord Injury Nursing, 9, 117-121.

Krause, J. S. (1992). Employment after spinal cord injury. Archives of Physical Medicine and Rehabilitation, $\underline{73}, 163-169$.

Krause, J. S. \& Crewe, N. M. (1990). Long term prediction of self-reported problems following spinal cord injury. Paraplegia, 28, 186-202.

Krefting, L. (1991). Rigor in qualitative research: The assessment of trustworthiness. American Journal of Occupational Therapy, 45, 214-222.

Krishnan, K. R., Glass, C. A., Jackson, H. F., \& Bingley, J. D. (1988). Patient and nursing staff perceptions of living and working on a spinal injuries unit. Paraplegia, 26, 287-292.

Lammertse, D. P. \& Yarkony, G. M. (1991). Rehabilitation in spinal cord disorders. 4. Outcomes and issues of aging after spinal cord injury. Archives of Physical Medicine and Rehabilitation, 72, S-309-S-311. 
Lathem, P. A., Gregorio, T. L., and Garber, S. L. (1985). High-level quadriplegia: An occupational therapy challenge. American Journal of Occupational Therapy, 39, 705-714.

Lassiter, R. A. (1977). Vocational implications for people with spinal cord injuries. In J. G. Cull \& R. E. Hardy (Eds.), Physical medicine and rehabilitation approaches in spinal cord injury (pp. 87-99). Springfield, IL: Charles C. Thomas.

Lassiter, R. A. (1984). Work adjustment techniques in lifestyle counseling. In W. R. Rule (Ed.), Lifestyle counseling for adjustment to disability. Rockville, MD: Aspen Systems.

Lundqvist, C., Siosteen, A., Blomstrand, C., Lind, B., \& Sullivan, M. (1991). Spinal cord injuries: Clinical, functional, and emotional status. SPINE, 16, 76-82.

MacDonald, M. R., Nielson, W. R., \& Cameron, M. G. P. (1987). Depression and activity patterns of spinal cord injured persons living in the community. Archives of Physical Medicine and Rehabilitation, 68, 339-343.

Maddox, S. (1987). Spinal network. Boulder: Spinal Network and Sam Maddox. Mattingly, C. (1991). The narrative nature of clinical reasoning. American Journal of Occupational Therapy, 45, pp. 998-1005.

McShane, S. L. \& Karp, J. (1993). Employment following spinal cord injury: A covariance structure analysis. Rehabilitation Psychology, 38, pp. 27-40.

Mills, C. W. (1973). The meanings of work throughout history. In F. Best (Ed.). The future of work (pp. 6-13). Englewood Cliffs, NJ: Prentice-Hall. 
Patterson, D. R., Miller-Perrin, C., McCormick, T. R., \& Hudson, L. D. (1993). When life support is questioned early in the care of patients with cervical-level quadriplegia. New England Journal of Medicine, 828, 506-509.

Patton, M. Q. (1990). Evaluation and qualitative research methods. Newbury Park, CA: Sage Publications.

Pedretti, L. W. (1990). Therapeutic activity. In L. W. Pedretti \& B. Zoltan (Eds.), Occupational therapy: Practice skills for physical dysfunction (pp. 210-229). St. Louis: Mosby.

Pendleton, H. M. (1990). Occupational therapists' current use of independent living skills training for adult inpatients who are physically disabled. In J. A. Johnson \& E. J. Yerxa (Eds.) Occupational science: The foundation for new models of practice. (pp. 93-108). New York: Haworth Press.

Pilsecker, C. (1990). Starting out: The fitst six months posthospital for spinal cordinjured veterans. American Journal of Physical Medicine \& Rehabilitation, $\underline{69}$, 91-95.

Rybski, D. (1992) A quality implementation of Title I of the American with Disabilities Act of 1990. American Journal of Occupational Therapy, 46, 409-418.

Schell, B. A., \& Cervero, R. M. (1993). Clinical reasoning in occupational therapy: An integrative review. American Journal of Occupational Therapy, 47, 605-610.

Siegel, M. S. (1974). The vocational potential of the quadriplegic. In N. Little, L. Stewart, G. Simmons \& B. Nobles (Eds.), Rehabilitation of the spinal cord injured (pp. 119-126). Little Rock: University of Arkansas. 
Spencer, E. A. (1993). Functional restoration: Neurologic, arthritic, orthopedic, cardiac, and pulmonary conditions. In H. L. Hopkins \& H. D. Smith (Eds.), Willard and Spackman's occupational therapy (pp. 621-656). Philadelphia: Lippincott.

Stensman, R. (1994). Adjustment to traumatic spinal cord injury. A longitudinal study of self-reported quality of life. Paraplegia, $\underline{32}, 416-422$.

Stephens, L. C., \& Pratt, P. N. (1989). School work tasks and vocational readiness. In P. N. Pratt \& A. S. Stevens (Eds.). Occupational therapy for children (pp. 311 334). St. Louis: Mosby.

Sudman, S., \& Sudman, N. M. (1982). Asking questions. San Francisco: Jossey-Bass. Sullivan, J. (1990). Individual and family responses to acute spinal cord injury. Critical Care Nursing Clinics of North America, 2, 407-414.

Taylor, B., Cupo, M. E., \& Sheredos, S. J. (1993). Workstation robotics: A pilot study of a desktop vocational assistant robot. American Journal of Occupational Therapy, 47, 1009-1013.

Taylor, D. (1974), Treatment goals for quadriplegic and paraplegic patients. American Journal of Occupational Therapy, 28, 22-29.

Thomas, C. L. (Ed.). (1993). Taber's cyclopedic medical dictionary. Philadelphia: F. A. Davis.

Trieschmann, R. B. (1980). Spinal cord injuries: Psychological, social and vocational adjustment. New York: Pergamon Press.

Trieschmann, R. B. (1992). Psychosocial research in spinal cord injury: The state of the art. Paraplegia, 30, 58-60. 
Velozo, C. A. (1993). Work evaluation: Critique of the state of the art of functional assessment of work. American Journal of Occupational Therapy, 47, 203-209.

Walker, R. A. (1974). Vocational rehabilitation of the quadriplegic. In N. Little, L. Stewart, G. Simmons, \& B. Nobles (Eds.), Rehabilitation of the spinal cord injured (pp. 127-135). Little Rock, AK: University of Arkansas.

Wehman, P., \& Moon, M. S. (1988). Vocational rehabilitation and supported employment. Baltimore: Paul H. Brookes.

Yarkony, G. M., Roth, E. J., Meyer, P. R., Lovell, L., Heinemann, A. W., \& Belts, H. B. (1990). Spinal cord injury care system: 15-year experience at the Rehabilitation Institute of Chicago. Paraplegia, 28, 321-329.

Yerxa, E. J., \& Locker, S. B. (1990). Quality of time use by adults with spinal cord injuries. American Journal of Occupational Therapy, 44, 318-326.

Zejdlik, C. P. (1992). Management of spinal cord injury. Boston: Jones and Bartlett. Zwecker, B. H. (1991). Social Security disability benefits: An overview. Connecticut Medicine, 55, 707-710. 


\section{APPENDIX A}

INTERVIEW GUIDELINES 


\section{INTERVIEW GUIDELINES}

\section{Tell me about your education and work before your injury.}

--What do you remember as being important to you about education?

--What do you remember as being important to you about your work?

--When you thought of your future, what role did work or education play?

--What were your goals?

--Were you employed at the time of your injury?

--Tell me about your typical work day before your injury.

\section{Tell me about your injury.}

--What was the cause of your injury?

--Did it ever occur to you that you might not be able to work?

--When did this occur?

--What was happening to you at that time that made you question your ability to work?

--Was your former employer supportive? Did he offer to keep your job or another job for you upon your release from the hospital?

-What went through your mind?

--Did you talk with people about your thoughts and feelings about work?

--Did they approach you? When?

--What did people say to you? 


\section{Tell me the story of your rehabilitation.}

--Describe a typical day in the hospital during your rehabilitation.

--Did you make any decisions about your life or your work while in rehabilitation?

--Tell me about your prevocational or vocational program in the hospital.

\section{Can you describe your experience in occupational therapy?}

--What involvement did the occupational therapist have in work issues?

--What was the best thing about occupational therapy? The worst?

--What would have been more helpful to you?

\section{Tell me about your life now.}

--Describe the process of going to work after your injury.

--Tell me about your work.

--Is it the same or similar to your previous work or your previous goals?

--Describe a typical work day.

--How do others respond to you as a worker?

--How does this differ from how you perceive yourself?

--What is satisfying to you about your work? Is this different from what satisfied you in your previous work?

--What has been/was difficult about returning to work?

--How does your work life now differ from your work life before your injury?

--How many jobs have you had since your injury?

--What was the length of time at each job?

--What was the reason for leaving each job?

--When you think about it, how do you make sense of the changes in your life?

--Tell me about your future plans or dreams. 
APPENDIX B

SUBJECT CONSENT FORM 
College of Applled Sciences and Arts - Dopertment of Occupational Therapy

One Washington Square • San José, California 95192-0059

Main Office: 408/924-3070 • Fieldwork Office: 408/924-3078 • FAX: 408/924-3088

\section{SUBJECT CONSENT FORM}

I understand that I have been invited to participate in Meredith Cooke's study of the meaning of work in the lives of men with spinal cord injuries. This study will partially fulfill requirements for her Master's degree in Occupational Therapy at San Jose State University. I am aware that she hopes to learn whether different individuals have had similar experiences in adjusting to their disability in regards to their work life and that she expects that the results of the study will be used to better educate occupational therapists to provide services needed by men with spinal cord injury as they prepare for eventual employment.

I am aware that I have been selected as a possible participant in the study because I have sustained a spinal cord injury and because work has been identified as an important issue for me.

I know that if I decide to participate, I will meet Ms. Cooke at a mutually agreeable time and location, and that she will ask questions about my past and present experiences. I am aware that because she would like to hear whatever I can tell her about my experiences without the distraction of taking notes, she will listen to and tape record all that I tell her, using prepared questions to guide the interview. The interview will last approximately two hours and can be split into two sessions.

I understand that any information that is obtained in connection with this study and that can be identified with me will remain confidential and will be disclosed only with my permission or as required by law. If I give my permission by signing this document, information I have given regarding my experiences with and perceptions of my vocational issues will be disclosed. However, no names will be mentioned, and it is not anticipated that it will be possible for anyone to identify me as distinguished from others participating in the study.

Participant's initials 
I understand that the results of this study will be presented to the Department of Occupational Therapy at San Jose State University, and will be submitted for publication in a national, professional journal.

I understand that if I decide to participate, I am free to discontinue participation at any time without prejudice.

I understand that there are no risks involved with my participation in this research. The researcher cannot and does not guarantee or promise that I will receive any benefits from this study. Other than the time I give to complete the interview, there will be no cost to me. I will not receive payment for my participation.

I AM MAKING A DECISION WHETHER OR NOT TO PARTICIPATE. MY SIGNATURE INDICATES THAT I HAVE DECIDED TO PARTICIPATE VOLUNTARILY, HAVING READ THE INFORMATION PROVIDED ABOVE.

I understand that if $I$ have any questions at any time that I should feel free to ask Ms. Cooke directly. If I desire, I will be given a copy of this form to keep. Complaints about the research may be presented to Amy Killingsworth, M.A., OTR, Interim Chair, Department of Occupational Therapy at (408) 924-3070 or to Karen Diaso-Serrett, Ph.D., OTR, FAOTA, advisor for Meredith Cooke, at (408) 924-3075. Questions or complaints about research subject's rights, or research-related injury may be presented to Serena Stanford, Ph.D., Associate Academic Vice President for Graduate Studies and Research, at (408) 924-2480.

Date

Signature of Participant
Date

Signature of Researcher 
APPENDIX C

FOLLOW-UP QUESTIONS 
FOLLOW-UP QUESTIONS

Name

Date

1. Length of stay in hospital

2. Length of stay in rehabilitation

3. Amount of movement initially.

4. Amount of movement during rehabilitation.

5. Amount of movement now.

6. How are you different as a person now compared to before your injury?

7. How are you different as a coworker since your injury?

8. If you had enough money that you didn't need to work, would you work?

What would you do? 